(C) <2019>. This manuscript version is made available under the CC-BY-NC-ND 4.0 license http://creativecommons.org/licenses/by-nc-nd/4.0/

The definitive publisher version is available online at https://doi.org/10.1016/j.energy.2019.07.165 


\title{
Experimental and Numerical Investigation of Performance of an Ethanol-Gasoline Dual-Injection Engine
}

\author{
Yuan Zhuang ${ }^{1}$, Guodong Zhu ${ }^{1}$, Zhen Gong ${ }^{1}$, Chenfang Wang ${ }^{1}$, Yuhan Huang ${ }^{2, *}$
}

\begin{abstract}
${ }^{1}$ School of Automotive and Transportation Engineering, Hefei University of Technology, Hefei, China
${ }^{2}$ School of Civil and Environmental Engineering, University of Technology Sydney, NSW 2007, Australia
\end{abstract}

*Corresponding author: Dr Yuhan Huang, Email: yuhan.huang@uts.edu.au

\begin{abstract}
Experiments and simulations were performed to investigate the effect of ethanol direct injection plus gasoline port injection (EDI+GPI) on engine performance. Gasoline direct injection plus GPI (GDI+GPI) was also tested as a reference to EDI+GPI. The experimental results showed that volumetric efficiency increased with the raise of direct injection ratio in both EDI+GPI and GDI+GPI conditions. The volumetric efficiency and IMEP of EDI+GPI were greater than that of GDI+GPI, due to the stronger charge cooling effect of EDI. Combustion process was improved by EDI when ethanol energy ratio (EER) was less than $42 \%$, however further increase of EER led to the deterioration of combustion process. Simulation results showed that ethanol's high laminar flame speed played a dominate role to the improvement of combustion process. Although EDI negatively affected the equivalence ratio around spark plug, this disadvantage was offset by the high laminar flame speed of ethanol, resulting in shorter initial and major combustion durations. Simulation results also found that combustion process was deteriorated when EER was greater than $42 \%$, which was mainly due to over-cooling and poor mixing of EDI. Regarding emissions, NO decreased while CO and HC increased with the raise of both EDI and GDI ratios.
\end{abstract}

Keywords: Port fuel injection; Direct injection; Ethanol; Gasoline; Dual injection; Combustion

\section{Highlights}

- EDI+GPI showed higher volumetric efficiency and IMEP than GDI+GPI did.

- EDI+GPI led to lower in-cylinder temperature and shorter combustion duration.

- Ethanol's high laminar flame speed was the main contributor to short combustion duration.

- $\mathrm{HC}$ and $\mathrm{CO}$ of EDI+GPI first decreased and then increased with the raise of ethanol ratio.

\section{Please cite this article as:}

Y. Zhuang, G. Zhu, Z. Gong, C. Wang, Y. Huang, Experimental and numerical investigation of performance of an ethanol-gasoline dual-injection engine. Energy 2019; 186: 115835.

https://doi.org/10.1016/j.energy.2019.07.165 


\section{Abbreviations}

\begin{tabular}{|llll|}
\hline CFD & Computational fluid dynamics & ICE & Internal combustion engine \\
DI & Direct injection & IMEP & Indicated mean effective pressure \\
EDI+GPI & Ethanol direct injection plus gasoline port injection & ISCO & Indicated specific carbon monoxide \\
EER & Ethanol energy ratio & ISHC & Indicated specific hydrocarbons \\
GDI & Gasoline direct injection & ISNO & Indicated specific nitric oxide \\
GDI+GPI & Gasoline direct injection plus gasoline port injection & PFI & Port fuel injection \\
GPI & Gasoline port injection & SI & Spark ignition \\
\hline
\end{tabular}

\section{Introduction}

Currently, there is growing focus on the development of electric vehicles worldwide. However, the current bottlenecks of electric vehicles (e.g. trade-offs between cost, energy density, weight and size of batteries, long recharging time and short driving range [1]) prohibit them to largely replace the internal combustion engine (ICE) powered vehicles. Therefore, ICEs will remain to be the dominate power source in the transport sector for the foreseeable future [2] and continuous improvement of ICE's efficiency and emissions is a major ongoing task [3, 4]. A variety of technologies are being developed to increase engine efficiency and to reduce emissions, such as bio- or renewable fuels, homogeneous charge compression ignition (HCCI), Miller cycle, higher boosting levels and compression ratios, cylinder deactivation, and dual-injection. Among those technologies, dual-injection is one promising technology which has the potential to explore the benefits of both bio-fuels and direct injection.

The dual-injection method was first commercialized by Toyota in its D-4S 3.5L engine in the purpose of improving air-fuel mixture formation process without using high tumble intake system. Simultaneous port and direct injection of gasoline can reduce the requirement for intake flow coefficient while maintaining a homogeneous air/fuel mixture [5, 6]. This technology was also used by Volkswagen later in its EA888 3Gen engines [7]. Cohn et al. proposed using dual-injection to flexibly control fuel usage and to explore alcohol's merits in knock suppressing to solve increasingly severe knocking problem in highly "downsized" spark ignition (SI) engines [8]. It was estimated that the combined effective octane number (RON+MON)/2 can be raised to 160 for ethanol and 180 for methanol in ideal condition. The great flexibility of ethanol direct injection plus gasoline port injection (EDI+GPI) method in fueling and active combustion control also breeds a new concept called "octane on demand". In this method, a cheap low-octane base-fuel and a high-octane booster are used simultaneously through two separate fueling systems to compose a fuel mixture with the optimum anti-knock ability to best fit the engine operating condition. This means that low-octane base-fuel can be used in light and medium load engine conditions. In full load engine conditions, the high-octane booster can be used alone or mixed with low-octane base-fuel together to form mixture with proper octane number to effectively suppress the high knock tendency. Ethanol, methanol, butanol and fine grade gasoline ( $\mathrm{RON} \geq 97$ ) can be used as high-octane booster and fuels with RON as low as 71, like naphtha, can be used as low-octane base-fuel. Engine efficiency and emissions are improved due to the optimal use of two fuels with different properties.

Using EDI+GPI as an octane boosting method for SI engines has been studied in recent years. Bromberg et al. $[8,9]$ compared the effect of EDI+GPI with DI and GPI only in an SI engine. The results revealed that 
EDI + GPI could enable the compression ratio to be raised by about 2-4 units and the inlet pressure had the potential to be further increased to 2.5 bar, due to the charge cooling effect of ethanol's high latent heat of vaporization and its high octane number. The engine could therefore be potentially downsized by a factor of two and the fuel efficiency could be increased by approximately $40 \% \sim 50 \%$ comparing with conventional GPI engines $[10,11]$. Stein et al. conducted tests on a 3.5 L turbocharged engine equipped with GPI and E85 DI. It showed that E85 DI demonstrated great potential in increasing the engine's anti-knock ability. By applying DI E85, the engine could be kept working at maximum break torque (MBT) timing even at break mean effective pressure (BMEP) of 21 bar. However, in gasoline DI conditions, the spark timing had to be retarded to avoid knock when BMEP was just above 7.0 bar [12, 13]. Zhu et al. evaluated the combustion characteristics of dualinjection. It was also found that the engine efficiency of the dual-fuel dual-injection mode was better than single-fuel dual-injection. Using ethanol fuel could lead to shorter combustion duration and less unburned emissions [14, 15]. Zhuang et al. [16, 17], Daniel et al. [18, 19] and Turner et al. [20, 21] found that volumetric efficiency was increased and $\mathrm{NO}_{\mathrm{x}}$ emissions were decreased in EDI+GPI combustion mode due to the cooling effect of EDI.

To further understand the mechanisms of EDI+GPI combustion mode and exploit its potentials in increasing engine anti-knock ability and combustion performance, the in-cylinder flows, fuel evaporation and mixing, combustion and emission formation processes have been numerically studied by several researchers. Kasseris and Heywood [22-24] used a three-dimensional computational fluid dynamics (CFD) model to quantify the charge cooling effect of EDI. The results indicated that the evaporation rate of ethanol fuel in low temperature engine conditions (light and medium load conditions in turbocharged engines or naturally aspirated engines) were much lower than gasoline. In high load conditions, ethanol fuel evaporation exhibited more effective charge cooling effect. Huang et al. studied the mixture preparation and combustion processes of EDI+GPI through an ANSYS FLUENT code. It was found that the evaporation of ethanol may over-cool the droplets concentrated zone, leading to rich mixture and low flame speed. Strong charge cooling effect, low adiabatic flame temperature and partially premixed combustion mode of EDI were the dominate factors contributing to the low combustion temperature in EDI+GPI engine, resulting in the great anti-knock capacity and low $\mathrm{NO}_{\mathrm{x}}$ [25-27]. Guilaume et al. demonstrated that the simulation of ethanol combustion was greatly different to naphtha base fuel combustion, mainly due to longer injection duration caused by low heating value of ethanol fuel. Both single and split DI strategies led to high droplets concentrated region, due to the different atomization and vaporization capability between ethanol and naphtha [28, 29].

The experimental and numerical studies reviewed above have shown the advantages of EDI+GPI over conventional GDI and GPI engines on thermal efficiency, emissions and engine downsizing, whilst the different properties between ethanol and gasoline require careful design of mixture preparation process. Experimental studies have confirmed that the volatility of ethanol was greater than that of gasoline only when temperature was above 375K [30-33]. The long injection duration of ethanol fuel due its low lower heating value may lead to high droplets concentration zone and negative effect on injection induced aerodynamics, incylinder tumble intensity and temperature distribution. Previous experimental studies also indicated that there was an optimal combination of EDI/GPI ratio, injection timing and injection pressure for each engine operating condition to achieve both high anti-knock capability and low emissions. Engine efficiency, knock suppression 
and emissions may deteriorate outside this optimal range.

Most of previous studies on EDI+GPI reported the experimental and numerical works separately. The micro and macro experimental outcomes on EDI+GPI combustion did not correlate together which may affect the comprehensive and accurate understanding of this dual-fuel combustion phenomenon. In this study, CFD simulation and engine experiments were used simultaneously to investigate the EDI+GPI engine performance. GPI+GDI and GPI only conditions were compared with EDI+GPI condition to demonstrate the effect of EDI on engine performance. CFD simulation results, including detailed in-cylinder flows, mixture formation, combustion and emissions, were used to assist the understanding of the corresponding experimental results.

\section{Engine setup and CFD model}

\subsection{Experimental Apparatus}

A single cylinder naturally aspirated motor-cycle engine was used to perform the experiments. Figure 1 demonstrates the schematic layout of the test engine and Table 1 shows its specifications. The engine was originally equipped with a GPI system and was modified by adding an EDI system. The GPI fuel pressure was constant at 2.5 bar and EDI common-rail fuel pressure could be adjusted between 30 and 120 bar according to the engine operating conditions and experimental needs. The original electronic control unit (ECU) was replaced by a self-developed one which enabled flexible control of engine parameters, including DI start of injection (SOI) timing/pressure/duration, PFI SOI timing/duration, lambda $(\lambda)$, and spark timing. The engine was coupled with a Land\&Sea eddy current dynamometer to maintain the speed and to measure the torque. An $80 \mathrm{~L}$ steel tank was used as a buffer to stabilize the intake air flow. The volume of the tank was about 320 times greater than the engine displacement.

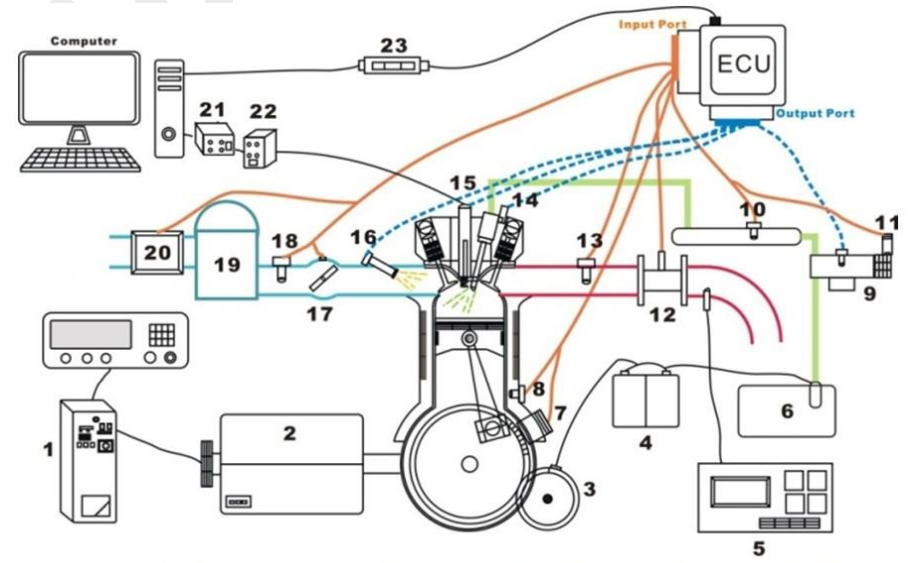

1. Dynamometer controller 2. Dynamometer 3. Start motor 4. Battery 5. Horiba MXEA-584L gas analyzer 6. Ethanol fuel tank 7. Encoder on crankshaft 8. Temperature sensor 9. High pressure fuel pump 10. Common rail pressure sensor 11. Encoder on high pressure pump shaft 12. Bosch wide-band lambda sensor 13 . Temperature Sensor 14. Direct fuel injector 15. Kistler spark plug pressure transducer 16. Port fuel injector 17. Throttle valve position sensor and driving motor 18. Temperature sensor 19. Inlet air regulator 20. Air flow meter 21. Combustion analyzer 22. Charge amplifier 23. CAN Communication module

Figure 1. Schematic of the engine system. 
Table 1. Engine specifications.

\begin{tabular}{ll}
\hline Engine type & Single cylinder, air cooled, 4-stroke, SOHC. \\
Displacement & $249.0 \mathrm{~cm}^{3}$ \\
Bore $\times$ stroke & $74.0 \mathrm{~mm} \times 58.0 \mathrm{~mm}$ \\
Compression ratio & $9.80: 1$ \\
Intake valve timing & Opening: $22^{\circ} \mathrm{BTDC}$, Closing: $54^{\circ} \mathrm{ABDC}$ \\
Exhaust valve timing & Opening: $55^{\circ} \mathrm{BBDC}$, Closing: $19^{\circ} \mathrm{ATDC}$ \\
\hline
\end{tabular}

The engine-out emissions were measured through a Horiba MEXA-584L gas analyzer. Exhaust samples were taken at $0.4 \mathrm{~m}$ downstream from the exhaust valve. Data was taken at $1 \mathrm{~Hz}$ sampling rate for 60 seconds for each test condition. $\mathrm{CO}$ and $\mathrm{HC}$ were measured by a Non-Dispersive Infrared (NDIR) detector and NO was measured via an electrochemical cell sensor. A Bosch wide-band lambda sensor was installed on the exhaust pipe line to control the air-fuel ratio (AFR) in gasoline only conditions. In EDI+GPI conditions, the AFR was monitored via the gas analyzer. The analyzer was configured for each fuel blending ratio by inputting the carbon/hydrogen $(\mathrm{H} / \mathrm{C})$ and carbon/oxygen $(\mathrm{C} / \mathrm{O})$ ratios. The in-cylinder pressure was acquired with a Kistler 6115B measuring spark plug pressure transducer via a Kistler 5011 charge amplifier. In each tested condition, in-cylinder pressure was averaged from 100 consecutive cycles with a resolution of 0.5 crank angle degree. The mass burnt fraction (MBF), combustion initiation duration (CA0-5\%), early combustion duration (CA5$50 \%$ ) and major combustion duration (CA5-90\%) were calculated from averaged in-cylinder pressure by using the method in Rassweiler et al. [34, 35].

The measurement uncertainties were calculated using the Kline and McClintock method [36]. Measurement uncertainties can be divided in types A and B. The type A uncertainty is obtained through a series of experimental measurements by:

$$
U_{A}=s^{2}=\frac{1}{j(j-1)} \sum_{j=1}^{j}\left(\overline{x_{j}}-\bar{x}\right)^{2} \text { Equation (1) }
$$

where $\mathrm{s}$ is the mean global variance, $j$ is the number of observations, $\overline{x_{j}}$ the mean values acquired for each point and $\bar{x}$ the mean of all acquired data. The type $\mathrm{B}$ uncertainty is dependent on the quantity measured, relating to previous measurements or calibration data of the sensors and is given by:

$U_{B}=\frac{B}{\sqrt{k}}$ Equation (2)

where B is related to instrument variable that leads to the uncertainty and $\mathrm{k}$ is a coefficient that takes into account the probability that the measured value can be found in a determined interval probability distribution. The combined measurement uncertainty is given by:

$$
U_{C}=U_{C}^{2}+_{B}^{2} \text { Equation (3) }
$$

For the variables derived from the directly measured quantities through some mathematical operation with the primary variables, the derivative method is used to determine the combined uncertainty:

$$
U_{C}^{2}=\sum_{i=1}^{N}\left[\frac{\partial f}{\partial x_{i}}\right]^{2} U_{C}\left(x_{i}\right) \quad \text { Equation (4) }
$$


where $f$ is the variable function of the directly measured variables and $U_{c}\left(x_{i}\right)$ is the combined uncertainty of each of the variables $x_{i}$. To ensure a $95 \%$ confidence level, the combined uncertainty are multiplied by a factor that expands the probability level within the t-student distribution.

Table 2 gives the calculated uncertainties as well as the device measurement accuracies. More details of the engine test rig can be found in Ref. [16].

Table 2. Sensors and their measurement uncertainties.

\begin{tabular}{ll}
\hline Parameters & Measurement uncertainty \\
\hline Speed & $0.3 \%$ of full scale \\
Torque & 0.03 of the output voltage \\
Air volumetric flow rate & $4.0 \%$ of the measurement \\
Gasoline mass flow rate & $1.8 \%$ of the measurement \\
Ethanol mass flow rate & $2.1 \%$ of the measurement \\
Bosch Lambda sensor & $1.7 \%$ of the measurement \\
Cylinder pressure & $0.5 \%$ of full scale \\
HC concentration & $3.2 \%$ of the measurement \\
NO $_{\mathrm{x}}$ concentration & $3.8 \%$ of the measurement \\
K-type thermocouples & $0.75 \%$ of the measurement \\
\hline
\end{tabular}

Table 3. Experimental conditions.

\begin{tabular}{|c|c|}
\hline Engine speed & $3500 \mathrm{rpm}$ \\
\hline Engine load & $\begin{array}{l}\text { Medium (IMEP 7.0 Bar, Throttle } \sim 35 \% \text { ); } \\
\text { Light (IMEP } \sim 5.0 \text { Bar, Throttle } \sim 25 \% \text { ) }\end{array}$ \\
\hline DI/PFI ratio & $0 \%, 18 \% \%^{\#^{*}}, 24 \%^{\#}, 30 \%^{\#}, 33 \%^{\&}, 36 \%, 42 \%, 48 \%$ \\
\hline GPI Injection timing & 300 CAD BTDC \\
\hline DI Injection timing & $300 \mathrm{CAD} B \mathrm{BTDC}$ \\
\hline Injection pressure & $\begin{array}{l}40 \text { Bar }(\text { When } E E R<48 \%) \\
60 \text { Bar }(\text { When } E E R \geq 48 \%)\end{array}$ \\
\hline Spark timing & 15 CAD BTDC (Original engine setting) \\
\hline
\end{tabular}

\section{2. $\quad$ Test Procedure}

The engine was first started with GPI only and warmed up until the lubricate oil temperature was stable. Then GPI fuel quantity was decreased and the EDI or GDI fuel quantity was increased until the designated EER (equation (5)) or GPI/GDI energy ratio was achieved. The engine speed was kept at 3500rpm. This was because the test engine was a motor-cycle engine with a relatively short stroke of $58 \mathrm{~mm}$. The engine operation became unstable (coefficient of variation of IMEP $\left.\left(\mathrm{COV}_{\text {IMEP }}\right)>5 \%\right)$ when the speed was less than 3000rpm. The total energy input of PFI and DI fuels was kept unchanged in both medium and light load engine conditions and the AFR was controlled by adjusting throttle position to maintain it at the stoichiometric value. The experimental conditions are shown in Table 3. Table 4 illustrates the properties of the fuels used in this study. 
Ethanol / gasoline energy ratio $(E E R)=\dot{H} E_{\text {Ethanol }} /\left(\dot{H} E_{\text {Ethanol }}+\dot{H} E_{\text {Gasoline }}\right)$ Equation (5)

where $\dot{H E}$ is the energy rate in $\mathrm{KJ} / \mathrm{s}$ and equals to fuel mass flow rate $(\mathrm{g} / \mathrm{s})$ times by its lower heating value.

Table 4. Test fuel properties.

\begin{tabular}{lll}
\hline Parameters & Ethanol & Gasoline \\
\hline Chemical formula & $\mathrm{C}_{2} \mathrm{H}_{6} \mathrm{O}$ & $\mathrm{C} 2-\mathrm{C} 14^{\mathrm{b}}$ \\
$\mathrm{H} / \mathrm{C}$ ratio & 3 & $1.795^{\mathrm{b}}$ \\
O/C ratio & 0.5 & 0 \\
Gravimetric oxygen content $(\%)$ & $34.78^{\mathrm{a}}$ & 0 \\
Density@ $20^{\circ} \mathrm{C}\left(\mathrm{Kg} / \mathrm{m}^{3}\right)$ & $790.0^{\mathrm{a}}$ & $744.6^{\mathrm{c}}$ \\
Research Octane Number & 106 & $95^{\mathrm{b}}$ \\
Stoichiometric air/fuel ratio & $9.0: 1$ & $14.79: 1^{\mathrm{b}}$ \\
LHV(MJ/kg) & $26.9^{\mathrm{a}}$ & $43.9^{\mathrm{b}}$ \\
LHV $(\mathrm{MJ} / \mathrm{L})$ & $21.3^{\mathrm{a}}$ & 31.9 \\
Enthalpy of vaporization $(\mathrm{kJ} / \mathrm{kg})$ & $854^{\mathrm{a}}$ & $350^{\mathrm{c}}$ \\
Temperature at boiling point $\left({ }^{\circ} \mathrm{C}\right)$ & $78.4^{\mathrm{a}}$ & $27-227^{\mathrm{c}}$ \\
\hline
\end{tabular}

a Provided by Manildra Group

${ }^{\mathrm{b}}$ http://www.environment.gov.au/atmosphere/fuelquality/publications/pubs/paper2.pdf

${ }^{\mathrm{c}}$ Heywood, J.B., Internal Combustion Engine Fundamentals. 1988: McGraw-Hill

\subsection{CFD Engine Model}

In this study, numerical simulation was performed through the CFD code ANSYS FLUENT. The simulation conditions were based on the experimental conditions shown in Table 3. The computational grid was generated based on the geometry of the EDI+GPI engine used in the experimental test. As shown in Figure 2 , the computational domain includes the geometry details of the combustion chamber, intake and exhaust valves, spark plug, throttle and intake and exhaust manifolds. The GPI injector was installed after the throttle and the DI injector was installed on intake valve side with a $15^{\circ}$ from the under surface of the cylinder head, and with a $12^{\circ}$ from the vertical surface. The EDI injector had 6 nozzles and had $34^{\circ}$ spray angle and $17^{\circ}$ bent axis [37]. The general grid size was $4.0 \mathrm{~mm}$ and the grids adjacent to the intake and exhaust valves were refined to $0.4 \mathrm{~mm}$. The mesh contains 178887 nodes, which was regarded as sufficient to perform the computations with a reasonable accuracy and low computational cost. The mesh independency study was carried out in Refs. [25-27].

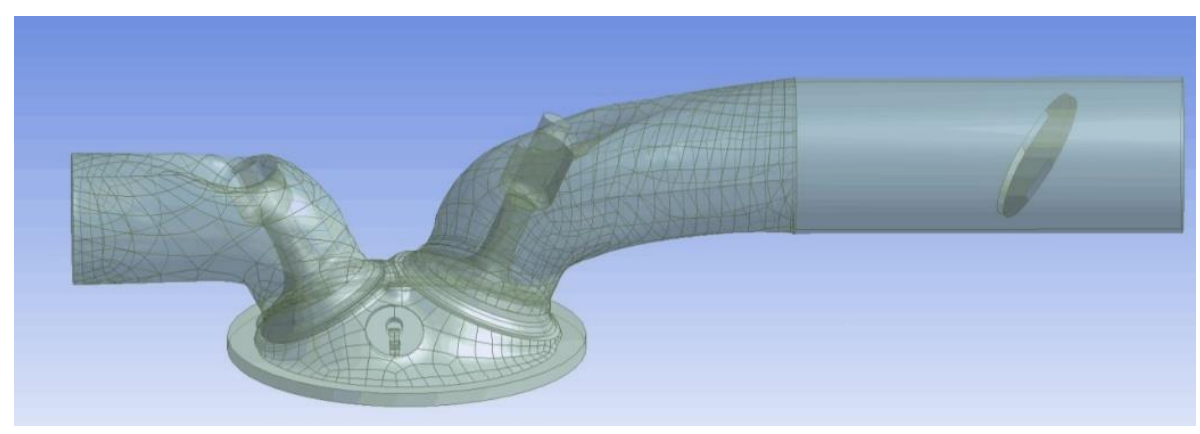

Figure 2. Computational domain. 
The in-cylinder flows were modelled by the RANS based realizable k- $\varepsilon$ model. DI and PFI sprays were simulated via Discrete Droplet Model (DDM) according to Eulerian-Lagrangian approach which was based on the Monte-Carlo statistical method. The Rosin-Rammler distribution method based on the blob injection concept and WAVE model were used for droplet primary and secondary breakup processes, respectively. The Extended Coherent Flame Model (ECFM) combustion model with the partially premixed combustion concept was adopted to simulate the dual-injection combustion process. The presumed Probability Density Function (PDF) look-up tables which were generated using complex reaction mechanisms were used to model the turbulence-chemistry interactions. For GPI only and GPI+GDI combustion modelling (single-mixturefraction), a three-dimensional PDF table was generated to determine the instantaneous scalar values in the turbulent flame. For EDI+GPI combustion modelling (two-mixture-fraction), a five-dimensional PDF table was generated to model the dual-fuel turbulence chemistry interaction. The instantaneous scalar values such as species mass fractions, density and temperature were calculated before combustion and stored in the PDF look-up tables. More details of the CFD model and DI injector were elaborated in $[26,38]$. Table 5 illustrates the computational models used for this study.

Table 5. Computational models.

\begin{tabular}{ll}
\hline Turbulence model & Realizable k- $\varepsilon$ model \\
Spray modelling approach & Discrete Droplet Model \\
Primary breakup model & Rosin-Rammler distribution method \\
Secondary breakup model & WAVE model \\
Distortion and drag & Dynamic Drag model \\
Wall-film model & Stanton and O'Rourke model \\
Evaporation model & Convection/Diffusion controlled model \\
Spark model & Zimont model \\
Combustion model & ECFM partially premixed combustion \\
NO model & Extended Zeldovich mechanism \\
\hline
\end{tabular}

\subsection{Verification of CFD engine model}

To verify the spray model, EDI spray experiments were performed in a constant volume chamber. The fuel injection pressure was $6 \mathrm{MPa}$, the ambient temperature was $350 \mathrm{~K}$, and the ambient pressure was $101 \mathrm{kPa}$. Figure 3(a) compares the experimental and numerical spray structures at $1.5 \mathrm{~ms}$ after the start of injection. As shown in Figure 3(a), the shape and length of the simulated spray agree well with the experimental results. Figures 3(b) and 3(c) compare the experimental and numerical in-cylinder pressures and heat release rates of EDI+GPI and GDI+GPI. The simulated in-cylinder pressure and heat release rate demonstrate good agreements with the experimental ones. Therefore, the CFD engine model is considered valid for modelling the EDI+GPI and GDI+GPI dual-injection combustion process. 

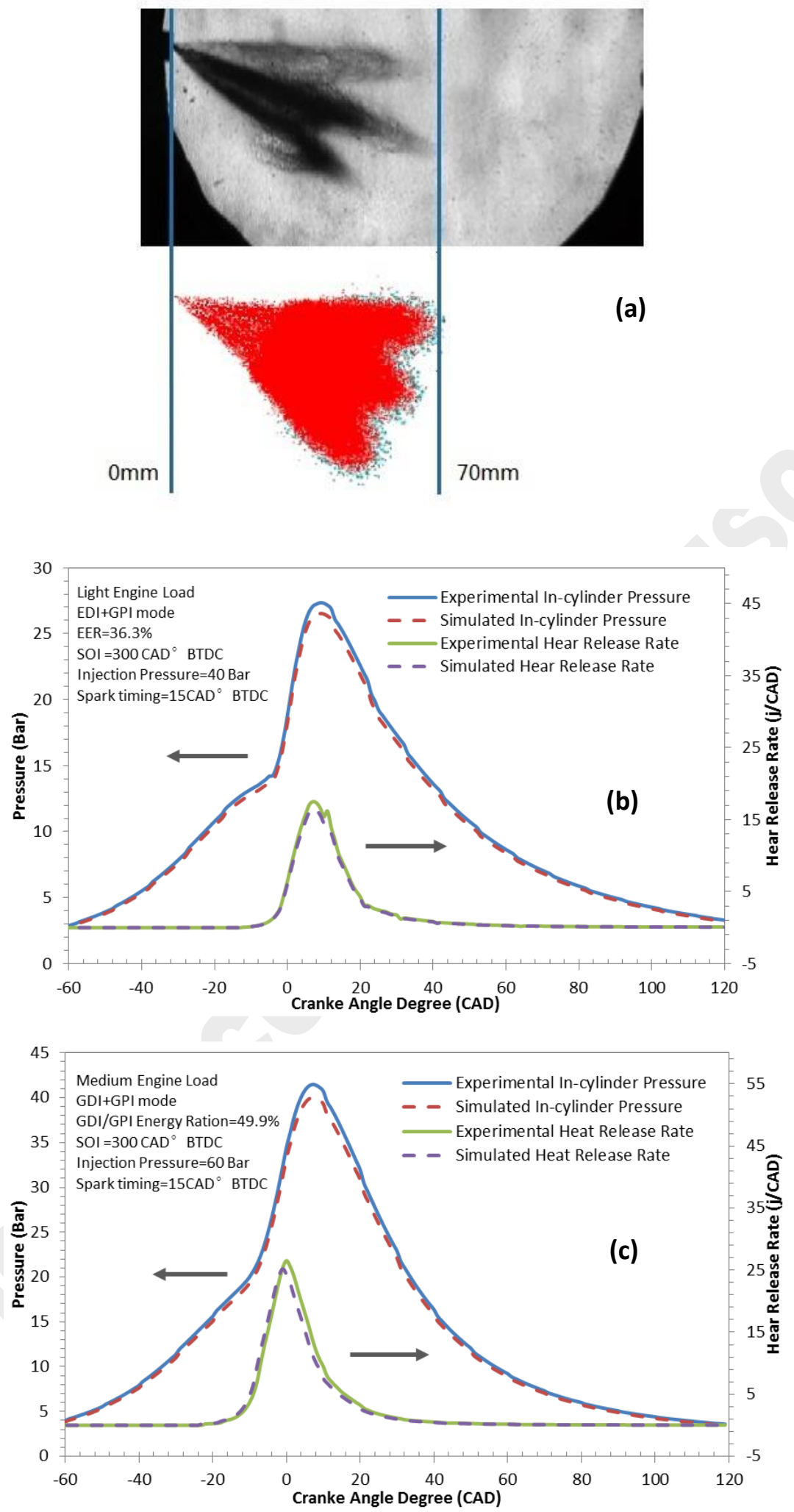

Figure 3. Comparison of the experimental and numerical results of spray morphology (a), in-cylinder pressure and heat release rate under EDI+GPI light load (b) and GDI+GPI medium load (c). 


\section{Results and discussion}

\subsection{Engine performance}

In this section, the engine experimental results of volumetric efficiency and IMEP are presented to compare the effect of EDI+GPI and GDI+GPI on engine performance. Numerical results are also presented to better understand the real-engine test results.

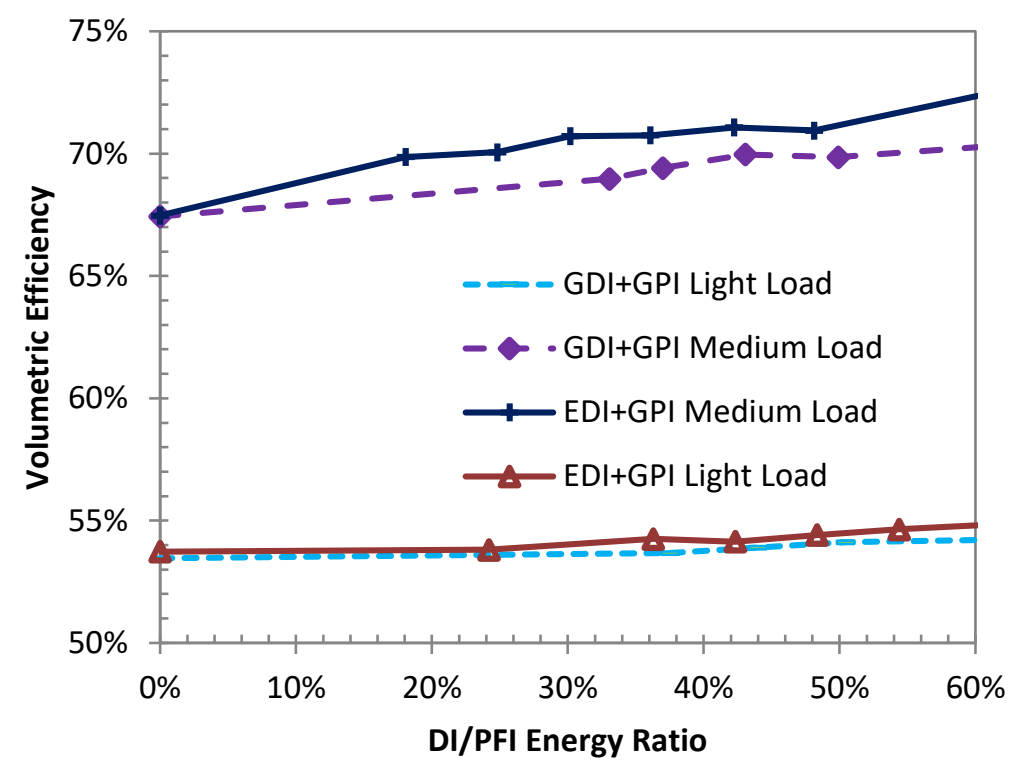

Figure 4. Variation of volumetric efficiency with DI/PFI energy ratio.

The variation of volumetric efficiency with DI/PFI energy ratio is shown in Figure 4. The volumetric efficiency is defined in Equation (6). Corresponding CFD results of evaporated and unevaporated ethanol and gasoline fuels are shown in Figure 5. As shown in Figure 4, the volumetric efficiency in both EDI+GPI and GDI+GPI conditions increases with the raise of the DI/PFI energy ratio. At light load, the volumetric efficiency in GDI+GPI conditions increases slightly by about $0.6 \%$ when the GDI/GPI ratio is increased from $0 \%$ to $60 \%$, while the volumetric efficiency increases by $1.2 \%$ in EDI + GPI conditions. At medium load, the volumetric efficiency increases by about $2 \%$ in GDI+GPI conditions and $4.5 \%$ in EDI+GPI conditions. When dualinjection mode is enabled, part of fuel is injected through DI injector with SOI at 300 CAD BTDC. The vaporization of DI fuel cools the fresh charge in the cylinder and raises its density, leading to the increased volumetric efficiency. The reduced partial pressure of port injected fuel is another factor contributing to the raised volumetric efficiency. From Figure 5, it can be seen that the unevaporated fuel in GDI+GPI mode at both light and medium engine loads actually slightly increases with the raise of DI/PFI energy ratio. In EDI+GPI mode, more fuel remains as liquid than that in GDI+GPI mode. This indicates that although the charge cooling of DI plays an important role in improving volumetric efficiency, the reduced partial pressure of port injected fuel also contribute a lot to the increase of volumetric efficiency. Another phenomenon should be noticed from Figures 4 and 5 is that although the unevaporated fuel in EDI+GPI condition is greater than that in GDI+GPI condition, the volumetric efficiency in EDI+GPI condition is always higher than that in GDI+GPI condition. This can be attributed to ethanol's greater latent heat of vaporization which is about 3 times gasoline's. 


$$
\text { Volumetric Efficiency }=\mathrm{m}_{1} / \mathrm{m}_{0} \quad \text { Equation (6) }
$$

where $\mathrm{m}_{1}$ is volume of air entered into the cylinder and $\mathrm{m}_{2}$ is volume of air equal to piston displacement.

From Figure 5, it can also be seen that the fuel in GDI+GPI condition at both light and medium loads has a higher completeness of evaporation than that in EDI+GPI condition. This is because gasoline's vapour pressure is bigger than ethanol's under low temperature condition ( $<375 \mathrm{~K}$ [23]). In GDI+GPI condition, the unevaporated fuel increases from 3.94 to $4.72 \mathrm{mg}$ at light load and from 5.05 to $5.80 \mathrm{mg}$ at medium load when $\mathrm{DI} / \mathrm{PFI}$ energy ratio increases. The slight raise of liquid fuel in GDI+GPI condition is related to the poor mixing, wall wetting and less time for fuel vaporization of DI. In EDI+GPI condition, the unevaporated fuel at high EDI/GPI energy ratio is less than that in low EDI/GPI energy ratio. The liquid fuels drops from 7.40 to 6.91 $\mathrm{mg}$ at light load and 7.92 to $6.89 \mathrm{mg}$ at medium load when EDI/GPI energy ratio increases. When EDI/GPI energy ratio is greater than $48 \%$, the DI pressure is increased from 40 to 60 bar, which may improve the atomization and mixing process of ethanol fuel and result in less unevaporated fuels. These liquid droplets will keep evaporating during the following compression and combustion processes, and may deteriorate the combustion process and lead to high $\mathrm{HC}$ and $\mathrm{CO}$ emissions (discussed in section 3.3).
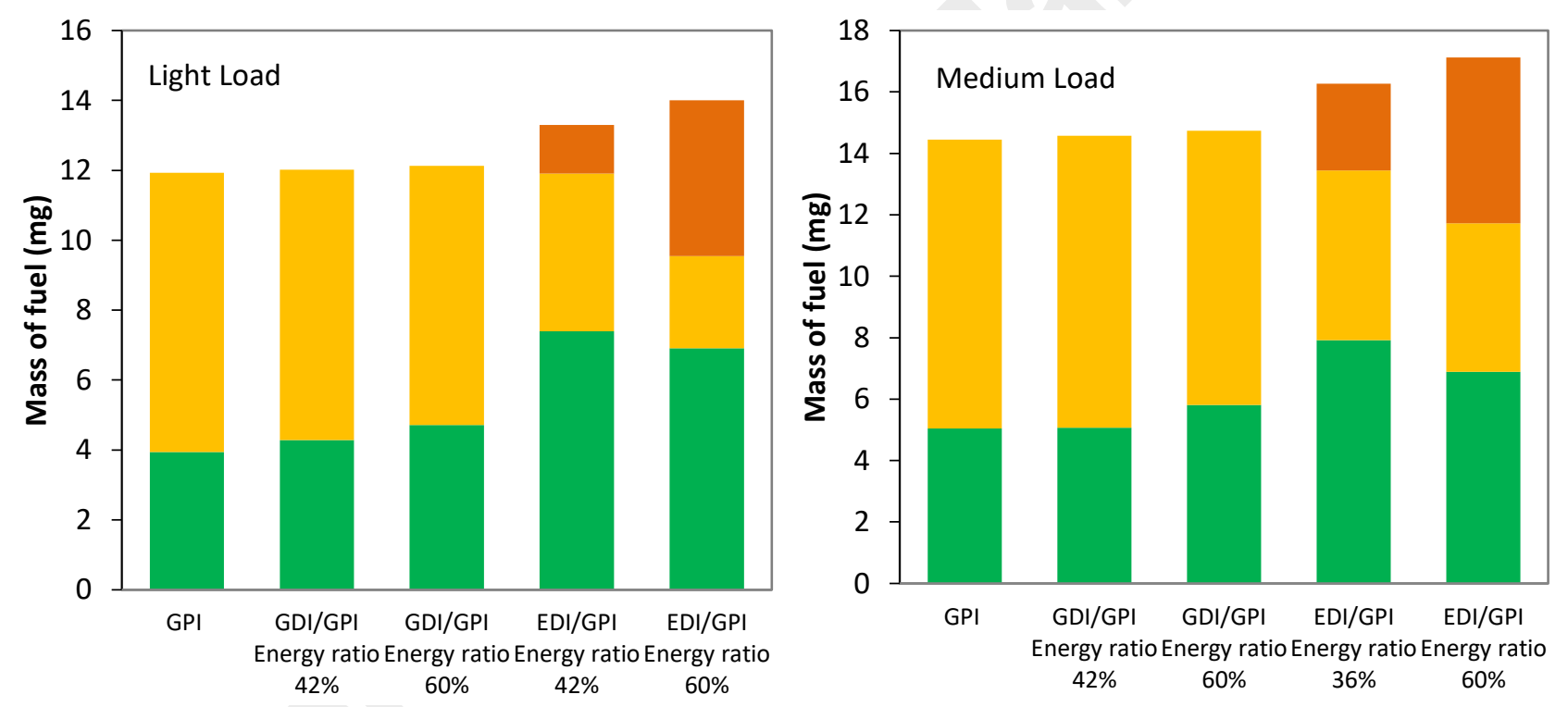

- Vapour Ethanol $\square$ Vapour Gasoline $\quad$ Liquid Fuels (Gasoline or Ethanol+Gasoline)

Figure 5. Variations of mass of the vapour and liquid fuels at IVC.

As the increment of volumetric efficiency in the GDI+GPI condition is less than that in the EDI+GPI condition, the IMEP is subsequently affected. As shown in Figure 6, when the DI/PFI energy ratio is increased from $0 \%$ to $60 \%$, the increase of IMEP in the EDI+GPI condition is quicker than that in the GDI+GPI condition at both loads. This result is mainly because when volumetric efficiency is increased, more fresh charge will flow into the cylinder, enabling the engine to work under slightly lean condition which improves the fuel combustion efficiency. Therefore, the IMEP increases with the increased volumetric efficiency. Additionally, for the EDI+GPI conditions, mole multiplier effect and ethanol's high flame propagation speed may also contribute to the IMEP increment. 


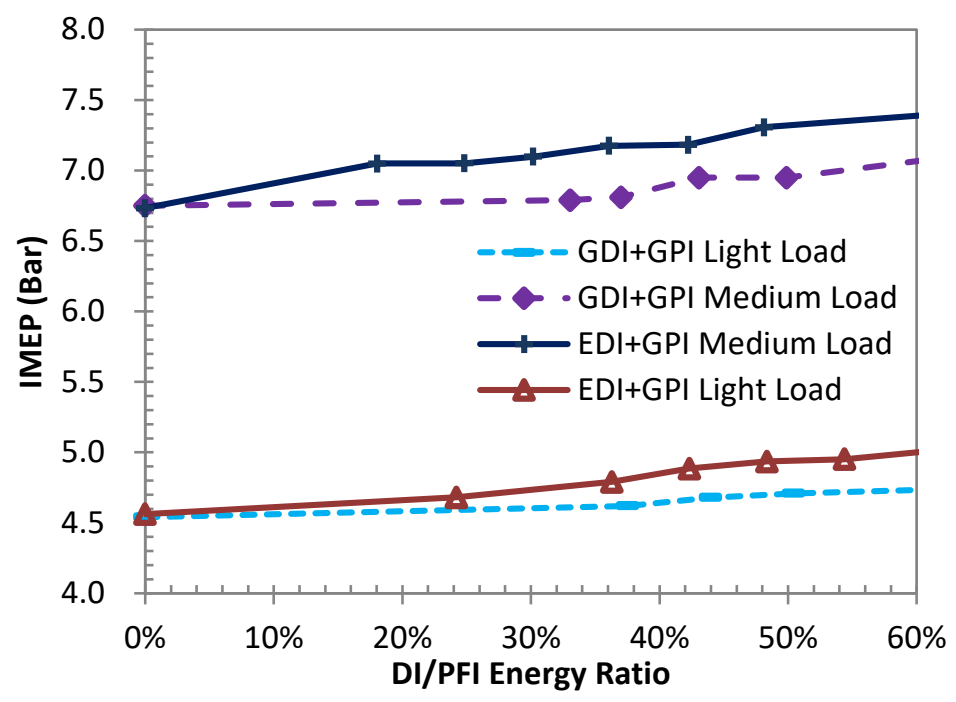

Figure 6. Variation of IMEP with DI/PFI energy ratio.

\subsection{Combustion characteristics}

The early combustion duration (CA5-50\%) and major combustion duration (CA5-90\%) are presented in Figures 7 and 8. A clear difference between EDI+GPI and GDI+GPI can be seen. As shown in Figures 7 and 8 , the early and major combustion durations in GDI+GPI condition almost linearly increase with the increase of the DI/PFI energy ratio, whereas in EDI+GPI condition, they first decrease and then increase with the increase of DI/PFI energy ratio. CA5-50\% in GDI+GPI condition increases about 2.5 CAD for light load and 2.0 CAD for medium load when the DI/PFI energy ratio is increased from $0 \%$ to $60 \%$. While in EDI+GPI condition, CA5-50\% first reaches the minimum of 15.5 CAD at medium load and 18 CAD at light load, and it then gradually increases to 19.5 and $21.0 \mathrm{CAD}$, respectively when DI/PFI energy ratio reaches $60 \%$. Similarly, CA5-90\% in the GDI+GPI condition increases from 45.0 to 48.5 CAD at light load and from 36.0 to 39.0 CAD at medium load when DI/PFI energy ratio is raised from $0 \%$ to $60 \%$. In EDI + GPI condition, it first decreases to 39.0 CAD at light load and 30.0 CAD at medium load, then it gradually increases to 43.0 and 33.0 CAD, respectively.

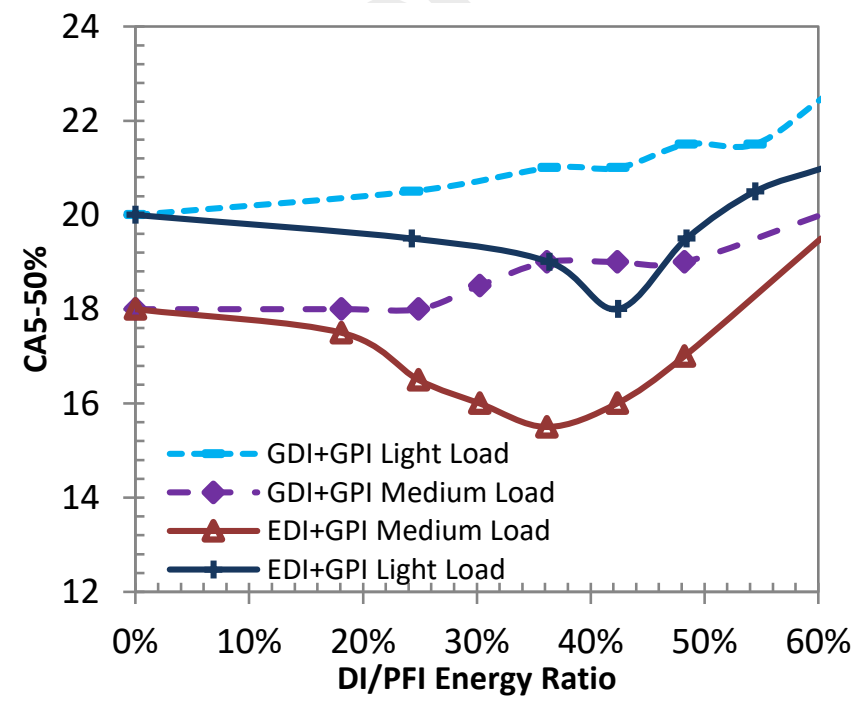

Figure 7. Variation of CA5-50\% with DI/PFI energy ratio. Figure 8. Variation of CA5-90\% with DI/PFI energy ratio.

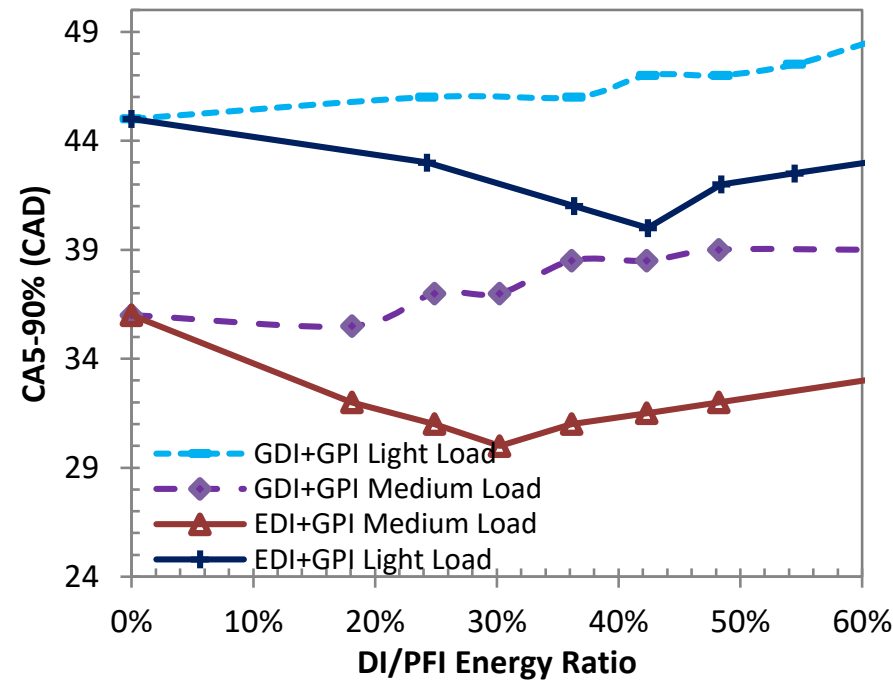


The different combustion results in GPI only, GDI+GPI and EDI+GPI conditions can be attributed to the synergetic effects of varied in-cylinder temperature distribution, distribution of equivalence ratio, fuel property, and in-cylinder turbulence. The distributions of in-cylinder temperature by spark timing, equivalence ratio by spark timing and flame propagation at 15 and 45 CAD ATDC are presented in Figures 9, 10 and 11, respectively in assistance for better understanding of the experimental results shown in Figures 7 and 8 . It should be noted in Figure 11 that in premixed combustion modelling, the progress variable is introduced to indicate the state of the reactants, where progress variable 0 stands for fresh mixture and progress variable 1 for burnt mixture. A value between 0 and 1 indicates the flame-brush.

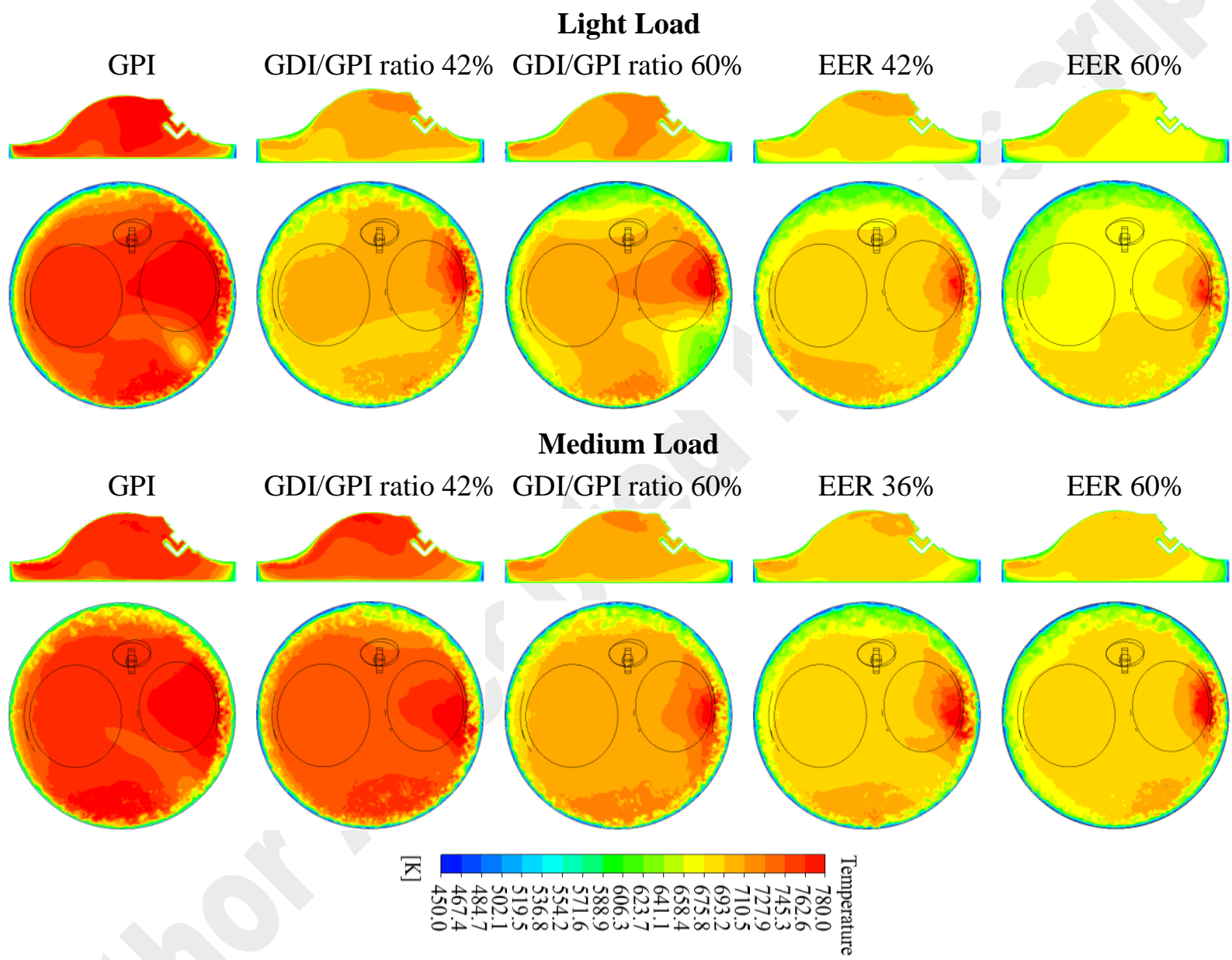

Figure 9. In-cylinder temperature distributions by spark timing (vertical plane and horizontal plane).

As shown in Figure 9, the in-cylinder temperature gradually decreases with the increase of DI/PFI energy ratio in GDI+GPI and EDI+GPI conditions. Both GDI and EDI show their effects in cooling the fresh charge. GPI conditions have the highest in-cylinder temperature before spark discharge at both light and medium loads. EDI results in the lower in-cylinder temperature and mean cylinder temperature in EDI+GPI condition is around $690 \mathrm{~K}$. When EER is $60 \%$ at light load, the large quantity of injected ethanol substantially cools the incylinder temperature which is generally below $670 \mathrm{~K}$. Normally, low temperature will impede the flame kernel formation and flame propagation process, leading to longer initiation combustion duration and early combustion duration. Thus, the CA5-50\% in GDI+GPI conditions prolongs with the increase of DI/PFI energy 
ratio. However, in EDI+GPI conditions, the CA5-50\% first decreases and then increases with the raise of EER. If considering the distribution of equivalence ratio around spark plug at spark timing (Figure 10), the high laminar flame and low ignition energy of ethanol fuel should be the main reasons that lead to the decrease of CA5-50\%. When the EER is further increased, in-cylinder temperature is too low and equivalence ratio around spark plug is too lean for flame propagation, leading to the increase of CA5-50\%.

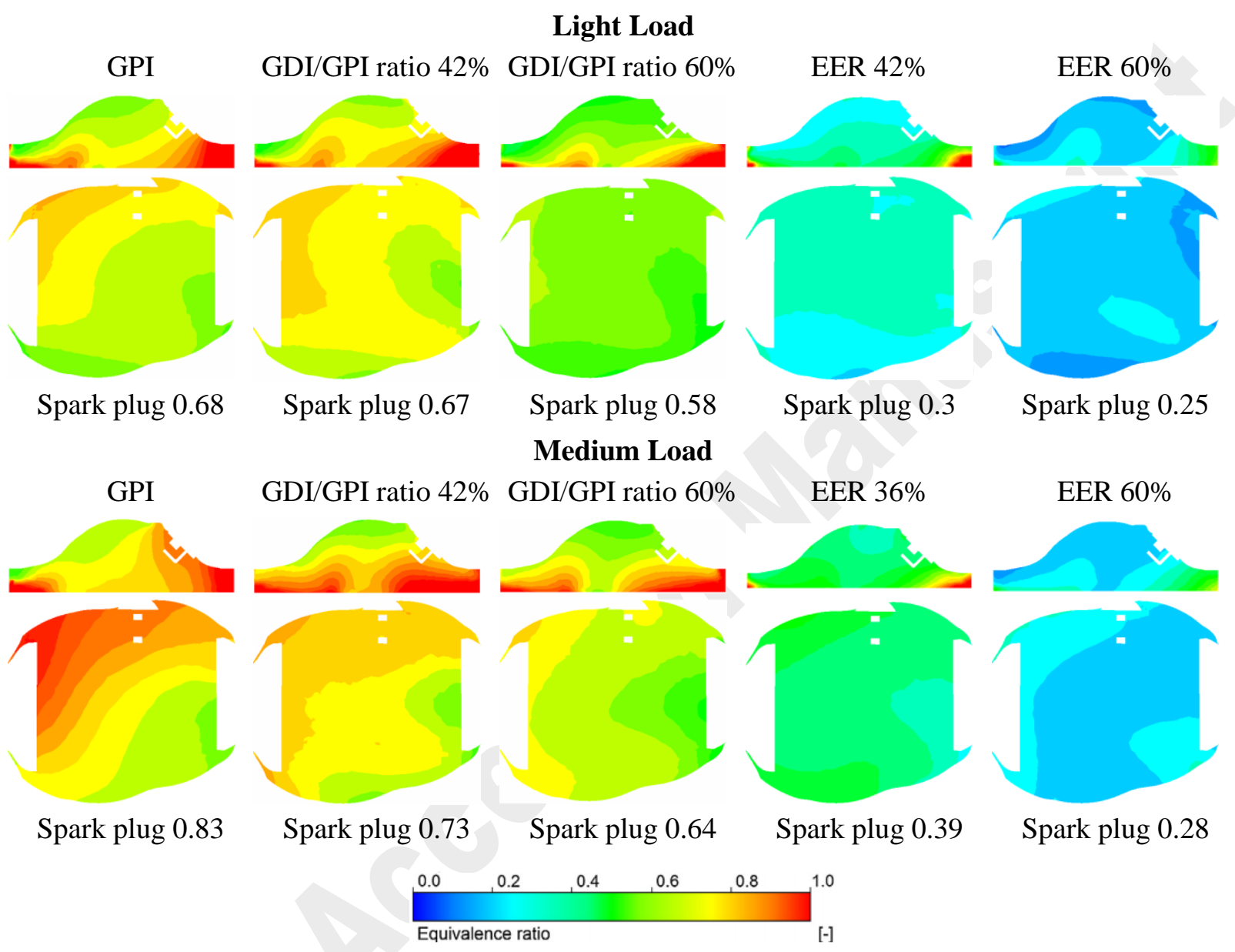

Figure 10. Distribution of equivalence ratio by spark timing (vertical plane and around the spark plug).

The distribution of equivalence ratio by spark timing is another factor that may impact the variation of CA5-50\%. As shown in Figure 10, equivalence ratio decreases with the increase of ethanol ratio in both EDI+GPI and GDI+GPI conditions. The GPI only conditions have the highest equivalence ratio at the spark plug position which is 0.68 at light load and 0.83 at medium load. When the engine is switched to EDI+GPI mode, the equivalence ratio around the spark plug largely decreases to be less than 0.5 and the lowest in light load is 0.25 and in medium load is 0.28 . This trend agrees with the results reported by Huang et al. [37]. Such a lean mixture is out of the ignitable equivalence ratio range of $0.5 \sim 1.5$ which may lead to a low flame speed and consequently long early combustion duration [39]. The overall lean equivalence ratio by spark timing in EDI + GPI conditions also indicated that part of ethanol fuel does not evaporate before combustion. This may further slowdown the flame propagation and extend the CA5-50\%. However, the CA5-50\% decreases when EER is less than $42 \%$. This decreasing trend further confirms that the effects of high laminar flame and low 
ignition energy of ethanol fuel overcome the negative impacts of low in-cylinder temperature, small equivalence ratio and poor mixing on early flame propagation period and play significant roles in EDI+GPI combustion. In GDI+GPI conditions, the equivalence ratio reduces with the raise of DI/PFI energy ratio. This may be caused by poor mixing when more gasoline is directly injected, which leads to more unevaporated liquid fuel before combustion (Figure 5). Generally, the equivalence ratio in GPI+EDI conditions is larger than that in GDI+GPI conditions due to higher vapour pressure of gasoline than ethanol's, leading to better completeness of evaporation of gasoline fuel (Figure 5).

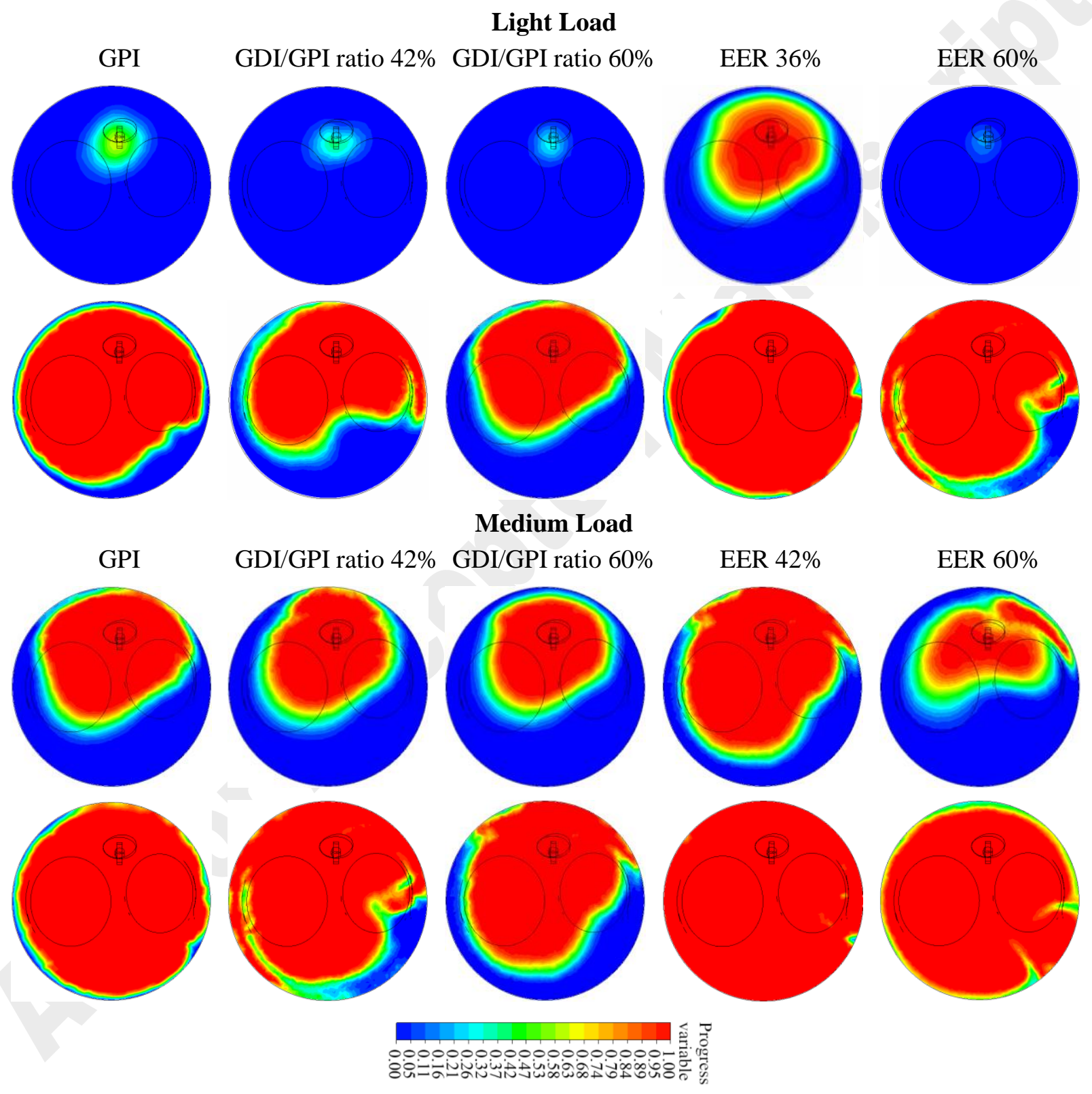

Figure 11. Flame propagation at 15 ATDC (top) and 45 ATDC (bottom) at light load and medium load.

Although EDI leads to lower in-cylinder temperature and equivalence ratio by spark timing, the flame propagation results have demonstrated its advantage in accelerating the combustion process. As illustrated in Figure 11, at both engine loads, the mixture burns more quickly in EDI+GPI condition than that in GPI only 
and GDI+GPI conditions when EER is less than $42 \%$. When the EER is greater than this value, the flame kernel formation and propagation processes are negatively affected by the low in-cylinder temperature and lean mixture (Figures 10 and 11), thus the mixture burns in a lower speed as shown at EDI/GPI energy ratio of $60 \%$. The GPI only condition has the highest in-cylinder temperature and equivalence ratio. However, these factors do not substantially accelerate the speed of burning. At 15 and 45 CAD ATDC, the mixture in GPI only condition burns faster than its GDI+GPI counterparts but slower than EER of $42 \%$ at light load and EER of $36 \%$ at medium load. The difference in combustion characteristics further confirms that in certain DI/PFI energy ratio ranges (less than $36 \%$ for light load and $42 \%$ for medium load in this study), EDI+GPI could result in better combustion performance than the GDI+GPI does due to ethanol's lower ignition energy and faster laminar flame speed. In the gasoline only mode (GDI+GPI), the increase of CA5-50\% and CA5-90\% is due to the deterioration of mixture quality caused by GDI and low flame speed of gasoline fuel.

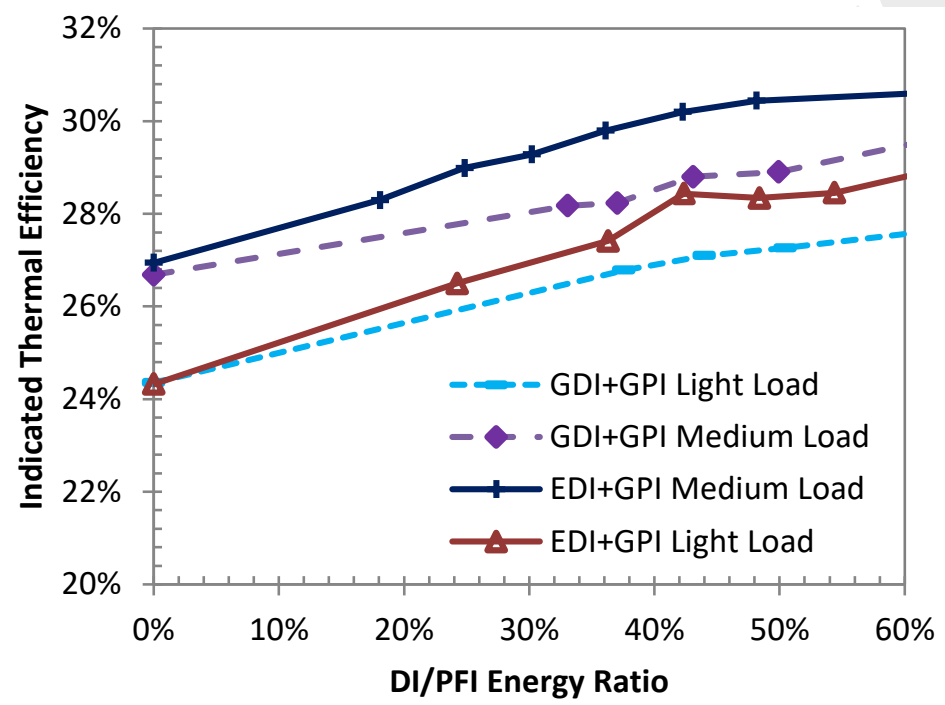

Figure 12. Variation of indicated thermal efficiency with DI/PFI energy ratio.

The differences in combustion characteristics and volumetric efficiency result in the difference in indicated thermal efficiency. As shown in Figure 12, the indicated thermal efficiency of EDI+GPI condition is increased faster than that of GDI+GPI condition. Higher volumetric efficiency (Figure 4) and higher combustion speed of ethanol fuel should be the main reasons that lead to the higher indicated thermal efficiency. It can also be seen that the diference of indicated thermal efficiency between EDI+GPI and GDI+GPI reaches the maximum when the DI/PFI energy ratio is in the range between $30 \%$ and $45 \%$. This is due to the relatively short combustion duration (Figures 7 and 8) in this range which advances the combustion phasing and reduces the heat losses, thus resulting in a higher indicated thermal efficiency. From the results presented in Figure 12, the following conclusions can be drawn: 1) DI can increase the engine efficiency in both EDI+GPI and GDI+GPI conditions due to the improved volumetric efficiency; 2) EDI is more effective than GDI in improving engine efficiency because of the enhanced charge cooling and optimized thermodynamic process (combustion product moles and less heat losses). 


\subsection{Emissions}

The variations of ISCO and ISHC with DI/PFI energy ratio are shown in Figures 13 and 14. Compared with EDI+GPI condition, the variations of ISHC and ISCO in GDI+GPI condition are monotonous. Both ISCO and ISHC increase with the increase of DI/PFI energy ratio in GDI+GPI condition. However, in EDI+GPI condition, ISCO and ISHC first decrease and then increase sharply with the increase of DI/PFI energy ratio. The ethanol's lower heating value is only about $60 \%$ of gasoline's (Table 4). In order to maintain the same energy input, the quantity of EDI should be increased, thus causing wall-wetting, especially in high DI/PFI energy ratios. This may contribute to the increase of ISCO and ISHC.

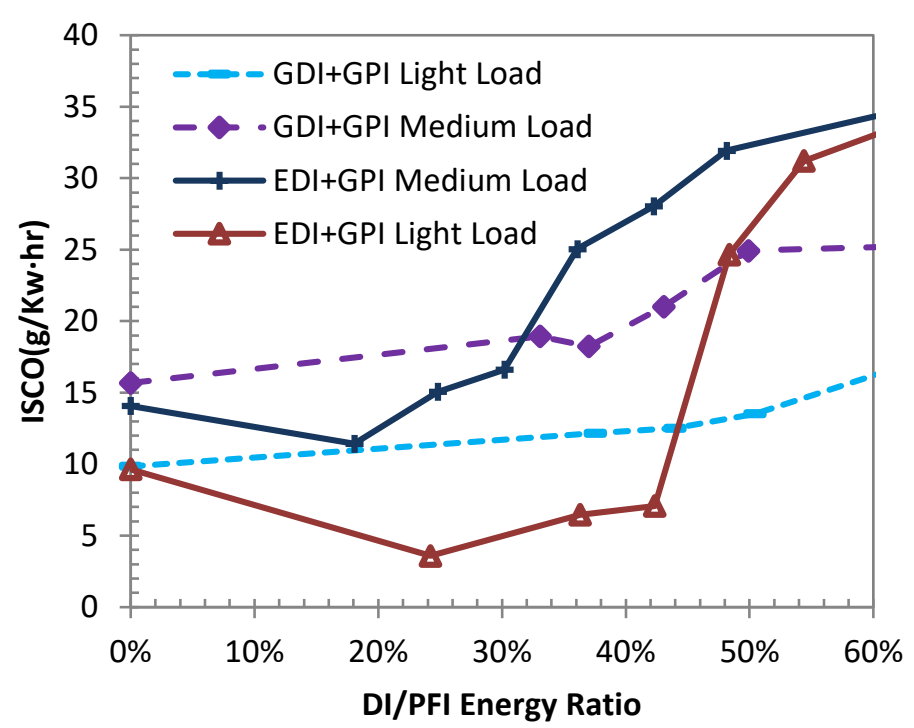

Figure 13. Variation of ISCO with DI/PFI energy ratio.

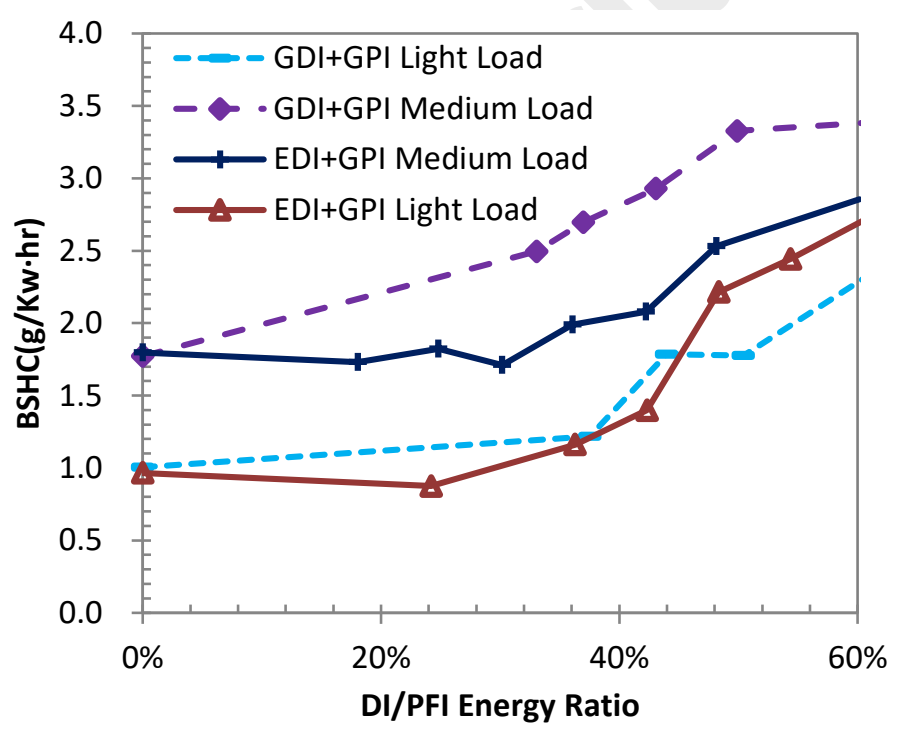

Figure 14. Variation of ISHC with DI/PFI energy ratio.

$\mathrm{CO}$ is an intermediate combustion product and is a result of incomplete combustion. Figure 15 illustrates the distributions of $\mathrm{CO}$ concentrations at EVO. It is obvious that the near wall regions have the highest $\mathrm{CO}$ concentrations at both engine loads. This is because the mixture in these regions is relatively richer than that in other regions, as shown in Figure 10 (vertical plane). Therefore, there is not enough oxygen for a complete burning. It can also be seen from Figure 15 that $\mathrm{CO}$ concentrations in near wall regions in EDI+GPI conditions are higher than that in GPI only and GDI+GPI conditions. Nevertheless, CO emissions in EDI+GPI conditions are found mostly in the near wall areas, which is different to GDI+GPI and GPI only conditions where high $\mathrm{CO}$ concentrated regions can be spotted inside the combustion chamber adjacent to the exhaust valve. On the whole, the simulated $\mathrm{CO}$ emissions trend agrees with the engine test results. The $\mathrm{CO}$ concentrations in GDI+GPI conditions are increased with the raise of DI/PFI energy ratio. The increased DI percentage leads to poor mixture (increased unevaporated liquid fuel, as shown in Figure 5), which should be the main reason. The decrease of $\mathrm{CO}$ emissions may be related to ethanol's fast combustion speed which optimizes the combustion process and ethanol's oxygen content which improves the oxidization process. When the EER is greater than $42 \%$, the great charge cooling of EDI may substantially reduce the in-cylinder temperature and equivalence ratio (as shown in Figures 9 and 10), which impedes the formation of the homogeneous mixture and therefore increases $\mathrm{CO}$ emissions. 


\section{Light Load}

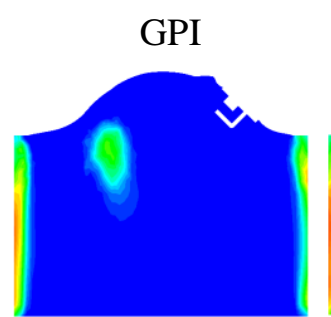

GDI/GPI ratio $42 \%$ GDI/GPI ratio $60 \%$

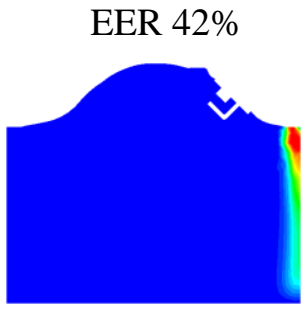

EER $60 \%$
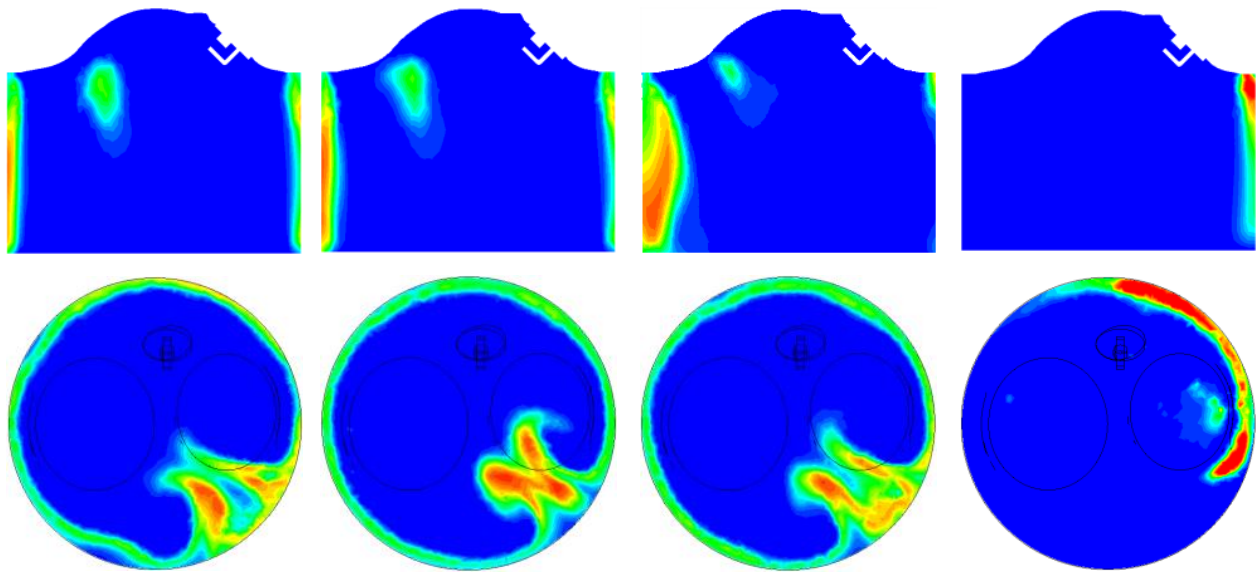

Medium Load

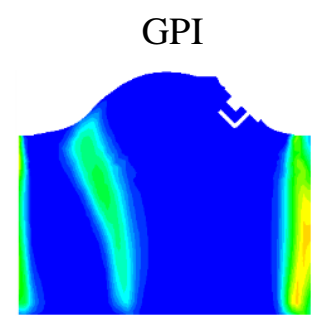

GDI/GPI ratio $42 \%$
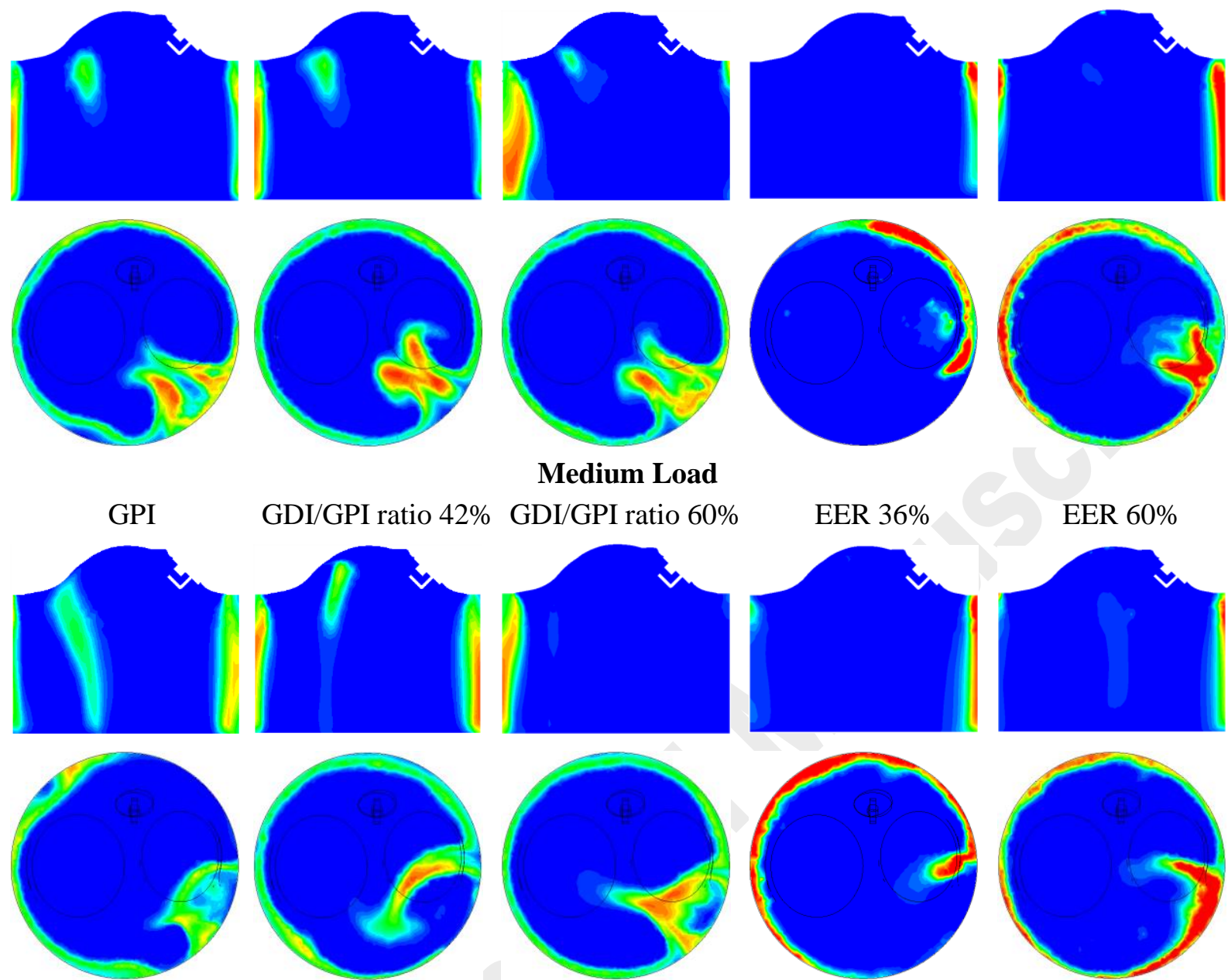

EER $60 \%$
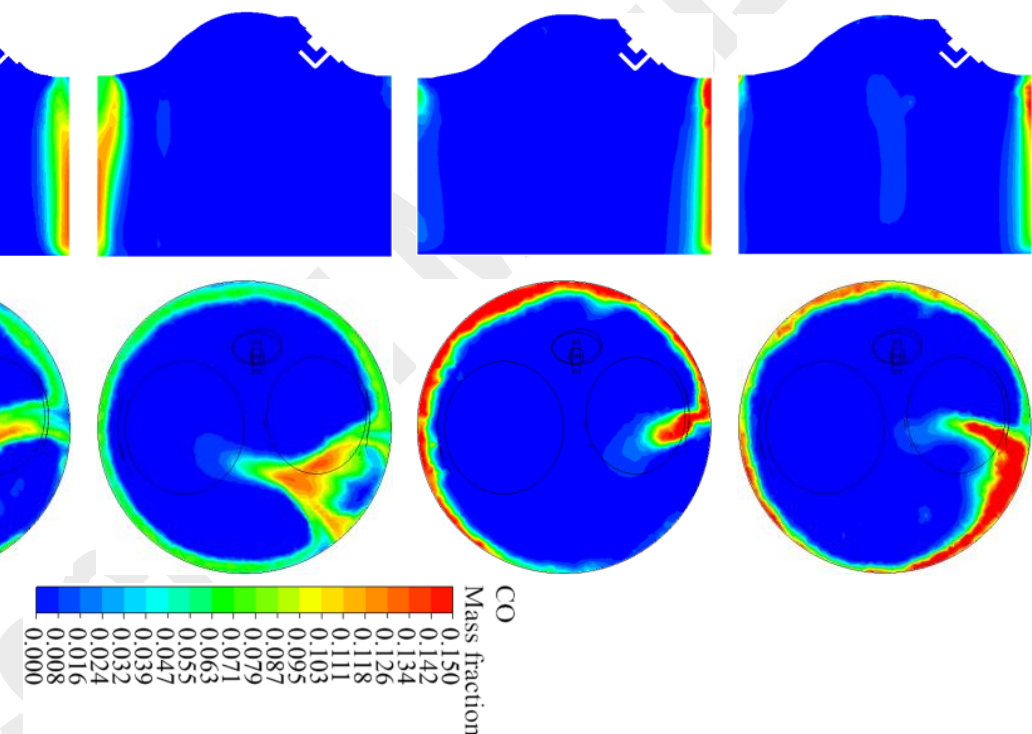

Figure 15. In-cylinder CO distributions at EVO (vertical plane and horizontal plane).
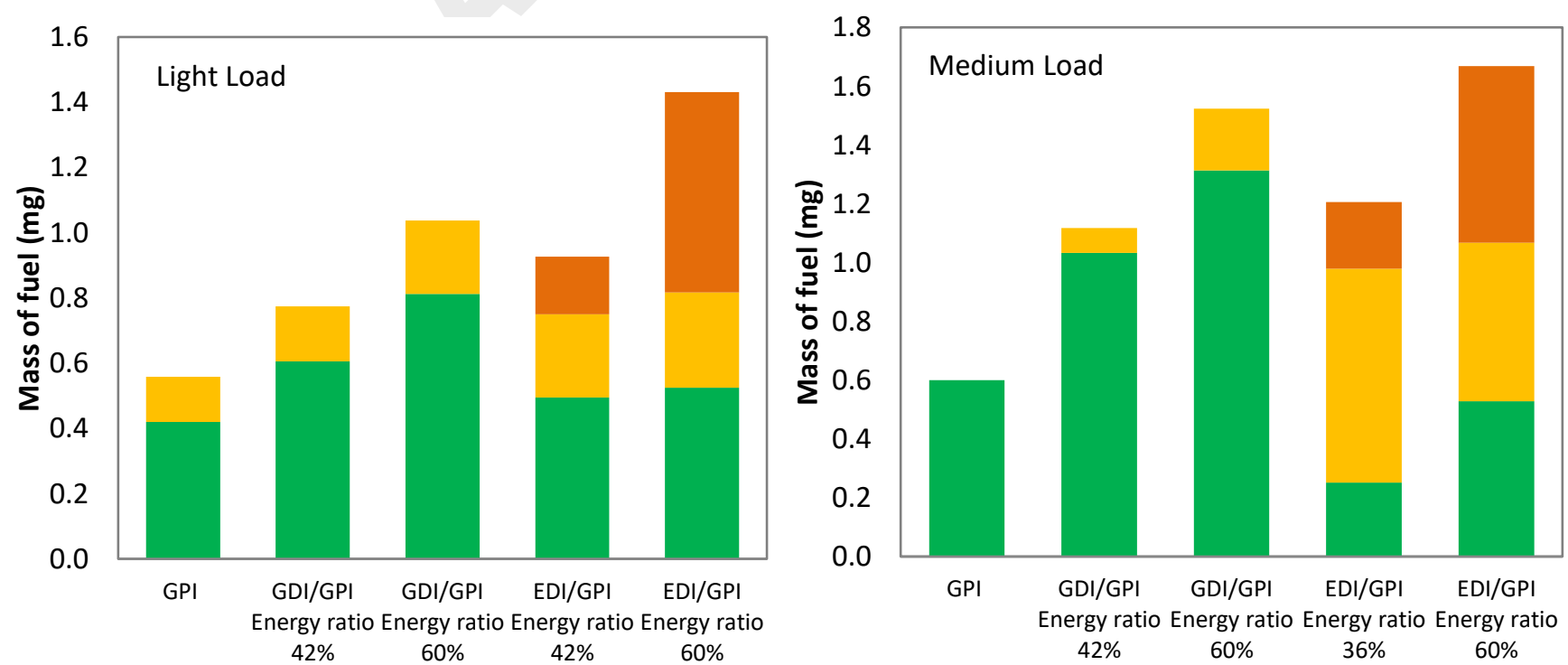

- Vapour Ethanol Vapour Gasoline $\quad$ Liquid Fuels (Gasoline or Ethanol+Gasoline)

Figure 16. Variations of mass of the vapour fuels and liquid fuels at EVO. 
$\mathrm{HC}$ emissions are mainly from unburnt and partially burnt fuel. Variations of mass of the vapor and liquid fuels at EVO are shown in Figure 16. The unburnt fuels (both vapor and liquid fuels) are augmented with the raise of DI/PFI energy ratio in GDI+GPI and EDI+GPI conditions, which indicates the increase of $\mathrm{HC}$ emissions (Figure 14). The increased unburnt fuels are related to the decreased in-cylinder temperature and reduced equivalence ratio as shown in Figures 9 and 10. Wall-wetting and poor mixture of GDI may also contribute to the increase of unburnt fuels in those conditions.

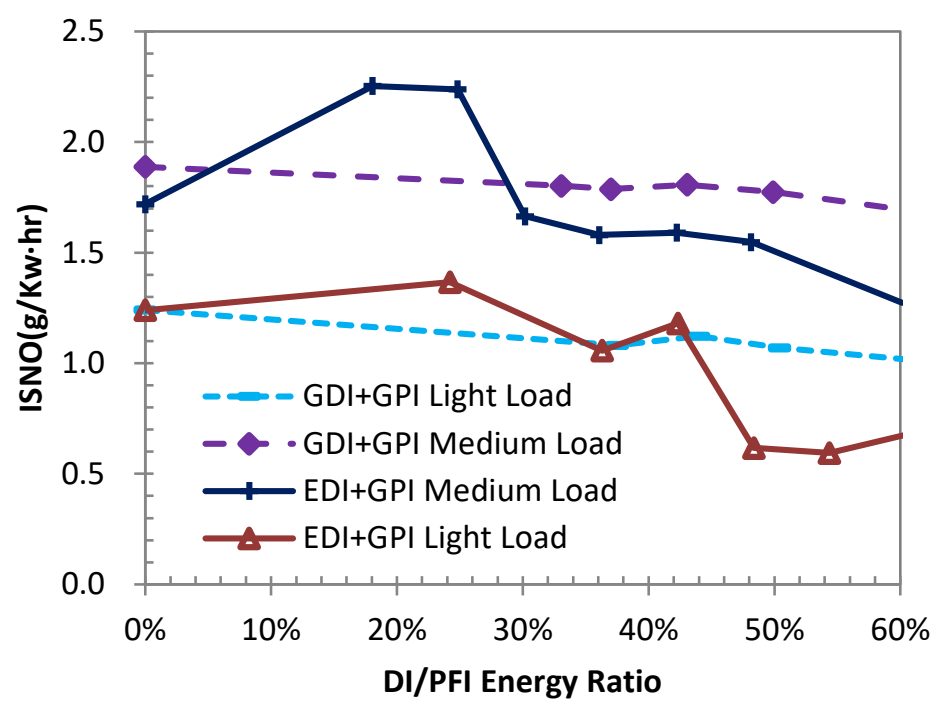

Figure 17. Variation of ISNO with DI/PFI energy ratio.

The variation of ISNO and the in-cylinder temperature distributions at EVO are shown in Figures 17 and 18, respectively. The variation of ISNO with the DI/PFI energy ratio is almost opposite to that of ISCO and ISHC. As shown in Figure 17, ISNO in GDI+GPI conditions slightly decreases with the increase of DI/PFI energy ratio. ISNO in EDI+GPI conditions first increases and then decreases when EER is greater than 25\%. The increase of ISNO should be related to the decreased combustion duration (Figures 7 and 8), which releases combustion energy more intensively, and hence increases the in-cylinder temperature. Further increases in EER when it is greater than $25 \%$ in EDI+GPI conditions can lead to a great charge cooling effect and low adiabatic flame temperature, which decreases the cylinder temperature and thereby results in a reduction of NO emissions (Figure 18). The linear decrease of ISNO in GDI+GPI conditions should be related to the charge cooling of GDI. However, this charge cooling effect is less obvious in GDI+GPI conditions than in EDI+GPI conditions which can be clearly seen from Figure 18. Therefore, NO emissions in GDI+GPI conditions are greater than those in EDI+GPI conditions when the EER is larger than $42 \%$.

GDI+GPI can only change the gasoline fuel ratio between DI and PFI, while EDI+GPI can change the mixture physicochemical properties due to the use of two different fuels. Increasing DI ratio in GDI+GPI condition only slightly enhances the charge cooling effect which increases the volumetric efficiency and changes the mixture quality which influences the $\mathrm{HC}$ and $\mathrm{CO}$ emissions. However, in EDI+GPI condition, the presence of ethanol in the combustion process directly affects the mixture burning rate and combustion temperature. Thus, in EDI+GPI condition, the combustion and emissions show different trends at different DI/PFI energy ratios. 


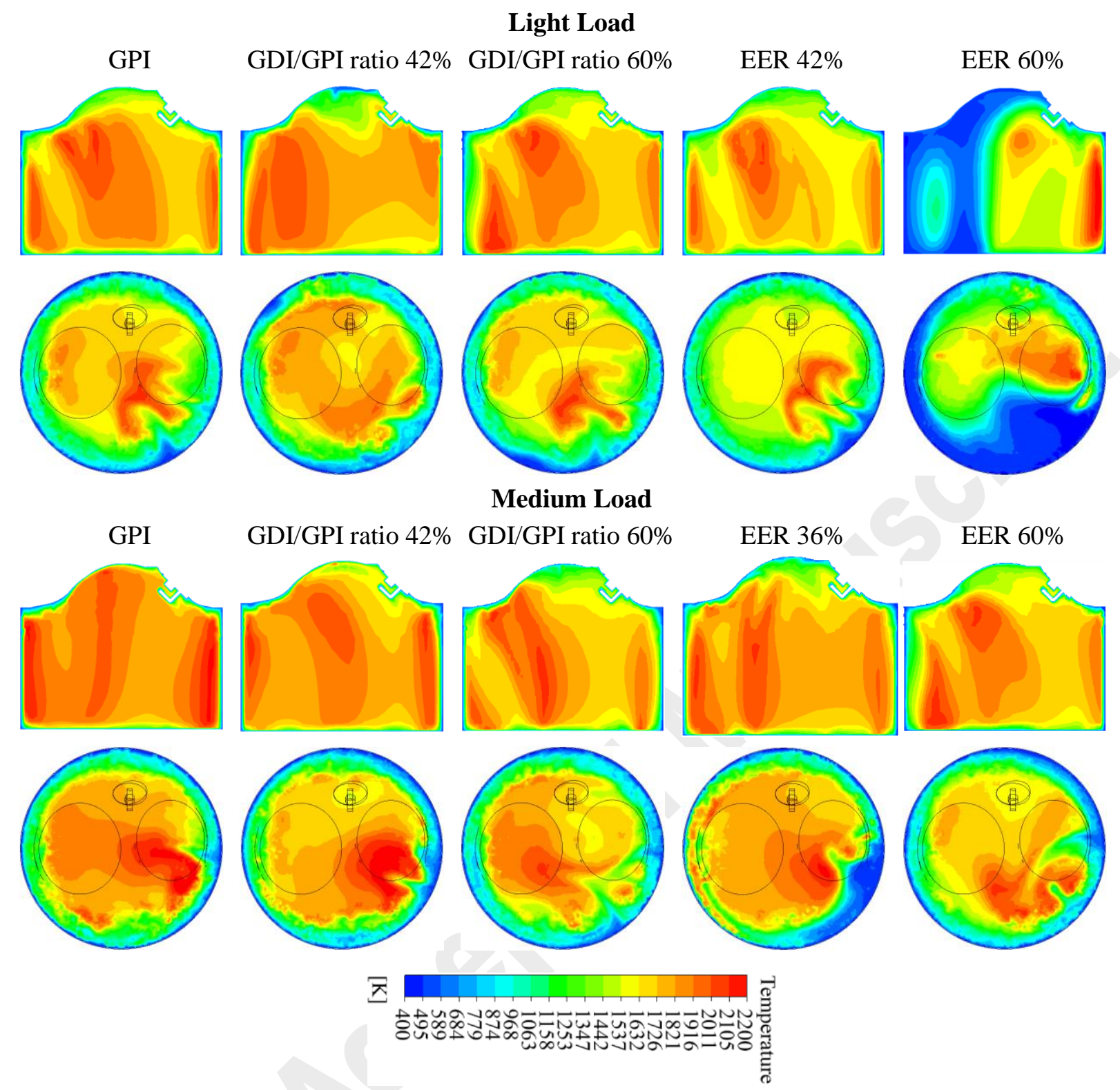

Figure 18. In-cylinder temperature distributions at EVO (vertical plane and horizontal plane).

\section{Conclusions}

In this study, experiments were conducted on a modified SI engine equipped with both PFI and DI systems. The effects of GDI and EDI on engine performance were investigated at engine speed of $3500 \mathrm{rpm}$ with DI/PFI energy ratio ranged from 0 (GPI only condition) to $60 \%$. GPI single-injection condition was compared with GDI+GPI and EDI+GPI dual-injection conditions. CFD simulations were performed for further understanding of experimental results. The major results can be summarized as follows:

1) IMEP increased with the increase of DI/PFI energy ratio in both GDI+GPI and EDI+GPI conditions. The raised volumetric efficiency caused by the charge cooling of DI was the main contributor. The charge cooling effect in EDI+GPI condition was stronger than that in GDI+GPI condition due to ethanol's greater enthalpy of vaporization. IMEP in EDI+GPI condition was generally higher than that in GDI+GPI condition. The greater charge cooling of EDI also caused negative affect to ethanol evaporation due to the lower ambient temperature. The mass of unevaporated fuel in EDI+GPI condition 
was slightly higher than that in GPI only and GDI+GPI conditions.

2) In EDI+GPI condition, CA5-50\% and CA5-90\% first decreased with the increase of EER when it was less than $42 \%$. However, further increase of EER would deteriorate the combustion, leading to the elongation of CA5-50\% and CA5-90\%. The decrease of CA5-50\% and CA5-90\% could be attributed to the high laminar flame speed of ethanol fuel. In GDI+GPI condition, CA5-50\% and CA5-90\% monotonously increased with the raise of DI/PFI energy ratio. Thermal efficiency in both GDI+GPI and EDI+GPI conditions increased with the raised of DI/PFI energy ratio.

3) At spark timing, the in-cylinder temperature and equivalence ratio around the spark plug generally decreased with the raise of DI/PFI energy ratio. EDI+GPI condition showed a relatively lower incylinder temperature and leaner mixture compared with their GDI+GPI counterpart. The strong charge cooling of EDI reduced the in-cylinder temperature before combustion which also impeded the vaporization and led to the lean mixture around the spark plug. However, the high laminar flame speed of ethanol fuel compensated the negative effect of low in-cylinder temperature and lean mixture on combustion and led to a faster flame propagation process than GDI+GPI condition.

4) In GDI+GPI condition, ISHC and ISCO increased with the increase of DI/PFI energy ratio. In EDI+GPI condition, ISHC and ISCO first slightly decreased and then increased with the raise of EER. Numerical simulation showed that high $\mathrm{CO}$ concentrated regions were mainly in areas near the cylinder wall and exhaust valve. ISNO in EDI+GPI condition first increased with the raise of EER and then decreased with further increase of EER due to the strong charge cooling and low adiabatic flame temperature of ethanol fuel. ISNO in GDI+GPI condition continually decreased with the raise of DI/PFI energy ratio.

\section{Acknowledgements}

This work was financially supported by the National Natural Science Foundation of China (Grant No. 51606056), Anhui Provincial Natural Science Foundation (Grant No. 1708085QE106), and Anhui Provincial Major Science and Technology Programs (Grant No. 17030901066).

\section{References}

[1] Y. Huang, N.C. Surawski, B. Organ, et al., Fuel consumption and emissions performance under real driving: Comparison between hybrid and conventional vehicles. Sci Total Environ 2019; 659: 275-282.

[2] G. Kalghatgi, Is it really the end of internal combustion engines and petroleum in transport? Appl Energy 2018; 225: 965-974.

[3] G.T. Kalghatgi, The outlook for fuels for internal combustion engines. Int J Engine Res 2014; 15: 383398.

[4] Agarwal A.K., Biofuels (alcohols and biodiesel) applications as fuels for internal combustion engines. Prog Energy Combust Sci, 2007, 33(3):233-271.

[5] T. Ikoma, S. Abe, Y. Sonoda, et al., Development of V-6 3.5-liter Engine Adopting New Direct Injection System. SAE Technical Paper 2006-01-1259, 2006.

[6] Wu X, Daniel R, Tian G, et al, Dual-injection: The flexible, bi-fuel concept for spark-ignition engines 
fuelled with various gasoline and biofuel blends. Appl Energy, 2011, 88(7):2305-2314.

[7] R. Wurms, M. Jung, S. Adam, et al., Innovative technologies in current and future TFSI engines from Audi. Aachen Colloquium Automobile and Engine Technology, 2011.

[8] D.R. Cohn, L. Bromberg, J.B. Heywood, Direct Injection Ethanol Boosted Gasoline Engines: Biofuel Leveraging for Cost Effective Reduction of Oil Dependence and CO2 Emissions. Massachusetts Institute of Technology, 2005.

[9] L. Bromberg, D.R. Cohn, J.B. Heywood, Calculations of knock suppression in highly turbocharged gasoline/ethanol engines using direct ethanol injection, Massachusetts Institute of Technology, 2006.

[10] D.R. Cohn, L. Bromberg, J. Heywood, Fuel Management System for Variable Ethanol Octane Enhancement of Gasoline Engines. in: U.S.P.a.T. Office, (Ed.). Massachusetts Institute Of Technology15 July, 2010.

[11] Bromberg L, Blumberg P, Cohn D R, et al. Gasoline engine system using variable direct ethanol injection and engine shutdown: U.S. Patent 7,637,250. 2009-12-29.

[12] R.A. Stein, C.J. House, T.G. Leone, Optimal Use of E85 in a Turbocharged Direct Injection Engine. SAE Int J Fuels Lubr 2009; 2: 670-682.

[13] Luján, José Manuel, Climent, Héctor, Novella R, et al, Influence of a low pressure EGR loop on a gasoline turbocharged direct injection engine. Appl Thermal Eng 2015, 89:432-443.

[14] G. Zhu, D. Hung, H. Schock, Combustion characteristics of a single-cylinder spark ignition gasoline and ethanol dual-fuelled engine. Proc IMechE Part D: Automobile Engineering 2010; 224: 387-403.

[15] Zhang X, Li C X , Xu J , Combustion Characteristics of a Single Cylinder Spark Ignition Engine Fueled with Coal Mine Methane. Journal of Beijing Institute of Technology, 2010, 19(3):298-304.

[16] Y. Zhuang, G. Hong, Primary investigation to leveraging effect of using ethanol fuel on reducing gasoline fuel consumption. Fuel 2013; 105: 425-431.

[17] Y. Zhuang, G. Hong, Effects of direct injection timing of ethanol fuel on engine knock and lean burn in a port injection gasoline engine. Fuel 2014; 135: 27-37.

[18] R. Daniel, C. Wang, H. Xu, et al. Dual-Injection as a Knock Mitigation Strategy Using Pure Ethanol and Methanol. SAE Int J Fuels Lubr 2012; 5(2):772-784.

[19] Birdsell S A, Willms R S, Dye R C , Pure Hydrogen Production from Octane, Ethanol, Methanol and Methane Reforming using a Palladium Membrane Reactor, IEEE Energy Conversion Engineering Conference, 1997.

[20] D. Turner, H. Xu, R.F. Cracknell, et al., Combustion performance of bio-ethanol at various blend ratios in a gasoline direct injection engine. Fuel 2011; 90: 1999-2006.

[21] Pan L, Zhang Y, Tian Z, et al, Experimental and Kinetic Study on Ignition Delay Times of Iso -Butanol. Energy \& Fuels, 2014, 28(3):2160-2169.

[22] E. Kasseris, J. Heywood, Charge Cooling Effects on Knock Limits in SI DI Engines Using Gasoline/Ethanol Blends: Part 1-Quantifying Charge Cooling. SAE Technical Paper 2012-01$1275,2012$.

[23] E. Kasseris, J. Heywood, Charge Cooling Effects on Knock Limits in SI DI Engines Using Gasoline/Ethanol Blends: Part 2-Effective Octane Numbers. SAE Int J Fuels Lubr 2012; 5: 844-854. 
[24] Anbari Attar M, Herfatmanesh M R, Zhao H, et al, Experimental investigation of direct injection charge cooling in optical GDI engine using tracer-based PLIF technique. Exp Thermal Fluid Sci 2014, 59:96108.

[25] Y. Huang, G. Hong, R. Huang, Investigation to charge cooling effect and combustion characteristics of ethanol direct injection in a gasoline port injection engine. Appl Energy 2015; 160: 244-254.

[26] Y. Huang, G. Hong, R. Huang, Numerical investigation to the dual-fuel spray combustion process in an ethanol direct injection plus gasoline port injection (EDI + GPI) engine. Energy Convers Manage 2015; 92: $275-286$.

[27] Y. Huang, G. Hong, R. Huang, Effect of injection timing on mixture formation and combustion in an ethanol direct injection plus gasoline port injection (EDI+GPI) engine. Energy 2016; 111: 92-103.

[28] G. Pilla, R. Kumar, O. Laget, et al., Simulation and Optical Diagnostics to Characterize Low Octane Number Dual Fuel Strategies: a Step Towards the Octane on Demand Engine. SAE Int J Fuels Lubr 2016; 9: 443-459.

[29] Rankovic N , Bourhis G, Loos, Mélanie, et al, Understanding octane number evolution for enabling alternative low RON refinery streams and octane boosters as transportation fuels. Fuel, 2015, 150:4147.

[30] R.A. Stein, D. Polovina, K. Roth, et al., Effect of Heat of Vaporization, Chemical Octane, and Sensitivity on Knock Limit for Ethanol - Gasoline Blends. SAE Int J Fuels Lubr 2012; 5: 823-843.

[31] Wang C , Janssen A, Prakash A, et al, Splash blended ethanol in a spark ignition engine - Effect of RON, octane sensitivity and charge cooling. Fuel, 2017, 196:21-31.

[32] H. Oh, C. Bae, K. Min, Spray and Combustion Characteristics of Ethanol Blended Gasoline in a Spray Guided DISI Engine under Lean Stratified Operation. SAE Int J Engines 2010; 3: 213-222.

[33] Y. Huang, S. Huang, R. Huang, et al., Spray and evaporation characteristics of ethanol and gasoline direct injection in non-evaporating, transition and flash-boiling conditions. Energy Convers Manage 2016; 108: 68-77.

[34] G.M. Rassweiler, L. Withrow, W. Cornelius, Engine Combustion and Pressure Development - Effects of Mixture Ratio, Spark Position, and Throttle Opening on Flame Pictures and Pressure Cards. Annals of Occupational Hygiene 1940; 40: 127-144.

[35] Marvin, Charles F, Jr , and R. D. Best, Flame Movement and Pressure Development in an Engine Cylinder. Technical Report Archive \& Image Library (1932).

[36] S.J. Kline, Describing Uncertainties in Single-Sample Experiments. Mechanical Engineering 1953; 75.

[37] Y. Huang, G. Hong, R. Huang, Numerical Investigation to the Effect of Ethanol/Gasoline Ratio on Charge Cooling in an EDI+GPI Engine. SAE Technical Paper 2014-01-2612, 2014.

[38] Y. Huang, S. Huang, P. Deng, et al., The Effect of Fuel Temperature on the Ethanol Direct Injection Spray Characteristics of a Multi-hole Injector. SAE Int J Fuels Lubr 2014; 7: 792-802.

[39] C. Netzer, T. Franken, L. Seidel, et al., Numerical Analysis of the Impact of Water Injection on Combustion and Thermodynamics in a Gasoline Engine using Detailed Chemistry. SAE Int. J. Engines 2018;11(6):1151-1166. 